\title{
Stephania japonica Ameliorates Scopolamine-Induced Memory Impairment in Mice through Inhibition of Acetylcholinesterase and Oxidative Stress
}

\author{
Md. Yusuf Al-Amin (D, ${ }^{1}$ Amitav Lahiry, ${ }^{1}$ Rafia Ferdous, ${ }^{1}$ Md. Kamrul Hasan, \\ Md. Abdul Kader, ${ }^{1}$ AHM Khurshid Alam, ${ }^{1}$ Zahangir Alam Saud, ${ }^{2}$ and Md. Golam Sadik (D) \\ ${ }^{1}$ Department of Pharmacy, University of Rajshahi, Rajshahi 6205, Bangladesh \\ ${ }^{2}$ Department of Biochemistry and Molecular Biology, University of Rajshahi, Rajshahi 6205, Bangladesh
}

Correspondence should be addressed to Md. Golam Sadik; gsadik2@ru.ac.bd

Received 11 August 2021; Revised 14 October 2021; Accepted 24 January 2022; Published 21 February 2022

Academic Editor: Abdeslam Jaafari

Copyright (c) $2022 \mathrm{Md}$. Yusuf Al-Amin et al. This is an open access article distributed under the Creative Commons Attribution License, which permits unrestricted use, distribution, and reproduction in any medium, provided the original work is properly cited.

\begin{abstract}
Alzheimer's disease (AD) is a progressive neurological disorder characterized by loss of memory and cognition. Stephania japonica is being used as traditional medicine in the treatment of different neurological problems. In this study, we evaluated the anticholinesterase and antioxidant activities of the crude methanol extract of S. japonica and its fractions in vitro and the neuroprotective effect of the most active fraction in the scopolamine-induced mouse model of memory impairment. Among the crude extract and its fractions, chloroform fraction exerted strong inhibition of acetylcholinesterase and butyrylcholinesterase enzymes with $\mathrm{IC}_{50}$ values of 40.06 and $18.78 \mu \mathrm{g} / \mathrm{mL}$, respectively. Similarly, the chloroform fraction exhibited potent antioxidant activity and effectively inhibited the peroxidation of brain lipid in vitro. The phytochemical profile revealed the high content of polyphenolics and alkaloids in the chloroform fraction. Pearson's correlation studies showed a significant association of anticholinesterase and antioxidant activity with alkaloid and phenolic contents. Kinetic analysis showed that the chloroform fraction exhibited a noncompetitive type of inhibition. In experimental mice, the chloroform fraction restored the impaired learning and memory induced by scopolamine as evidenced by a significant decrease in latency time and increase of quadrant time in probe trial in Morris water maze task. The chloroform fraction also significantly reduced the activity of acetylcholinesterase and oxidative stress in mice. Our results suggest that the chloroform fraction of $S$. japonica may represent a potential candidate for the prevention and treatment of $\mathrm{AD}$.
\end{abstract}

\section{Introduction}

Alzheimer's disease $(\mathrm{AD})$ is commonly characterized by dementia deteriorating over the years and usually affects geriatric people. The pathological hallmarks of AD include significant deficiency of cholinergic neurons, the emergence of senile plaques comprising $\beta$-amyloid $(\mathrm{A} \beta)$ protein, and neurofibrillary tangles of microtubule-associated protein tau [1]. Oxidative stress and insufficient cholinergic functionality in the brain are considered two vital events in the development of $\mathrm{AD}[2,3]$. Despite the reasonable progress in perceiving the etiology and pathogenesis of $\mathrm{AD}$ in recent years, the effective drugs remain limited.
It is widely accepted that the cholinergic system that facilitates the deposition and retrieval of elements in memory is compromised in $\mathrm{AD}$ [4]. The diminished cholinergic transmissions along with depletion of acetylcholine (ACh) are held responsible for the generation and progression of dementia [5]. Thus, aiming to inhibit cholinesterase enzymes, which are responsible for hydrolyzing acetylcholine, has evolved as a major strategy in treating AD. Donepezil, galantamine, and rivastigmine are the only anticholinesterase agents approved by the US Food and Drug Administration for AD therapy till now. These drugs have been found to ameliorate the symptoms with improvement in the performance of $\mathrm{AD}$ patients; however, none of these 
drugs proved to be successful in restricting or reversing the development of the disease [6]. Therefore, explorations need to be continued for novel agents with potential efficacy and considerable safety.

Further, it has been revealed that oxidative stress plays a significant role in the pathogenesis of $\mathrm{AD}$. The intervention of $\mathrm{AD}$ brain exhibited a high level of oxidative stress markers like reactive oxygen species (ROS), malondialdehyde (MDA), oxidized proteins, and DNA [7]. A mutual relation between oxidative stress and $\mathrm{A} \beta$ protein has been reported in several studies concluding the induction of oxidative stress by $\mathrm{A} \beta$ and elevated generation of $\mathrm{A} \beta$ by oxidative stress [8]. In fact, enhanced oxidative stress is hypothesized as an initial marker of $\mathrm{AD}$ pathogenesis contributing to further neuronal damage and cell death [3]. Therefore, the administration of potential antioxidative agents is suggested to minimize the ROS-mediated injury in AD.

Medicinal plants have been proved to be the potential source of remedies for various diseases, including $\mathrm{AD}$. In Bangladesh, many plants have been used in traditional medicine to treat $\mathrm{AD}$ or related neurological disorders. Scientific evaluation of this medicine may lead to the development of new drugs or establishing them as alternative medicine. Stephania japonica (Thunb.) Miers, locally known as Foat pata, is a common scrambler belonging to the family Menispermaceae and grown throughout Bangladesh. The plant is traditionally used in the treatment of vertigo, headache, and sleep disturbances. The leaves are used to cure fever and pain and as a tonic $[9,10]$. In Ayurveda and Sidha, the plant is being used in the treatment of various ailments, including bowel disorders, stomachache, dyspepsia, dysentery, diarrhoea, birth control, piles, urinary troubles, and heart troubles, and used as hypotensive and spasmolytic [11]. Biological investigations using in vitro and in vivo models have shown that the plant possesses multiple pharmacological effects, such as antioxidant, anti-inflammatory, cytotoxic/anticancer, analgesic, and hypoglycemic effects [12, 13]. Phytochemical analyses identified the hasubanan alkaloids as the major constituents along with phenolics and flavonoids, tannins, and steroids as minor constituents [13-15].

Although S. japonica has multiple therapeutic uses in traditional medicine, limited works have been done on its biological activity. Until now, there are no reports of the effect of this plant on neurological disorders. Therefore, the present study was designed to evaluate the crude methanol extract of $S$. japonica and its four solvent fractions for anticholinesterase and antioxidant activity in vitro and for neuroprotective effect in a scopolamine-induced mouse model of memory impairment.

\section{Materials and Methods}

2.1. Chemicals. Folin-Ciocalteu reagent, DPPH (1, $1^{\prime}$ diphenyl-2-picrylhydrazyl), aluminum chloride, potassium ferricyanide, and ammonium molybdate were procured from Sigma-Aldrich, India. 2-Deoxy-D-ribose, 2-thiobarbituric acid (TBA), bromocresol green (BCG), catechin, quercetin, 5,5'-dithio-bis-(2-nitro) benzoic acid (DTNB), acetylthiocholine iodide (ATCI), and S-butyrylthiocholine iodide (BTCI) were obtained from Sigma-Aldrich, Germany. All the employed chemicals were of analytical grade.

2.2. Plant Material. The stems of Stephania japonica were amassed from Rajshahi City, Bangladesh, in September 2018 and verified by an expert taxonomist (Collection number: 369). A voucher specimen was submitted for preservation in the herbarium affiliated with the Department of Botany, University of Rajshahi, Bangladesh.

2.3. Extraction. The coarse powder $(1.2 \mathrm{Kg})$ of the stems was soaked in methanol for extraction at room temperature and kept for 7 days with occasional shaking and stirring. After filtration, the methanolic extract was concentrated in a rotary evaporator at reduced pressure to obtain the crude methanolic extract (CME, $85.7 \mathrm{gm})$. The resulting extract (50.0 gm) was partitioned with solvents of different polarity using the modified Kupchan method to yield the corresponding fractions: ethyl acetate (EAF, $2.41 \mathrm{gm})$, chloroform (CHF, 21.63 gm), petroleum ether (PEF, 5.16 gm), and aqueous (AQF, 10.26 gm) fractions [16]. All the fractions obtained were utilized for further chemical and biological experiments.

2.4. Phytochemical Screening of the Plant Extract. Qualitative tests were performed on the CME and its fractions to detect the presence of different phytochemicals, including phenolics, flavonoids, alkaloids, saponins, and phytosterols, using the standard phytochemical methods as described earlier [17].

2.4.1. Estimation of Total Phenolic Content (TPC). The TPC of the extract and fractions from S. japonica was determined by the Singleton method (1965) using Folin-Ciocalteu reagent (FCR) with gallic acid as standard [18]. Sample/ standard solution $(0.5 \mathrm{~mL})$ was mixed with FCR (10 times diluted with distilled water, $2.5 \mathrm{~mL}$ ) and $\mathrm{Na}_{2} \mathrm{CO}_{3}$ solution $(7.5 \%, 2.5 \mathrm{~mL})$ in the test tube and left at room temperature for 25 minutes in a dark place. The absorbance of the solution was measured at $760 \mathrm{~nm}$. The result was calculated from the standard curve of gallic acid and expressed as mg of gallic acid equivalent (GAE)/g of dried extract.

2.4.2. Estimation of Total Flavonoid Content (TFC). The TFC of the extract and fractions from S. japonica was determined by aluminum chloride colorimetric method described by Dewanto et al. (2002) [19] using catechin as standard. Sample/standard solution $(1 \mathrm{~mL})$ was taken in the test tube, to which distilled water $(5 \mathrm{~mL})$ and $\mathrm{NaNO}_{2}(5 \% \mathrm{w} /$ $\mathrm{v}, 0.3 \mathrm{~mL})$ were added. After 5 minutes, $\mathrm{AlCl}_{3}(10 \% \mathrm{w} / \mathrm{v}$, $0.6 \mathrm{~mL})$ and $\mathrm{NaOH}(1 \mathrm{M}, 2 \mathrm{~mL})$ were added to the mixture, and a final volume of $10 \mathrm{~mL}$ was made with distilled water. The reaction mixture was kept at room temperature for 30 minutes and then the absorbance of the solution was measured at $510 \mathrm{~nm}$. The result was calculated from the 
standard curve of catechin and expressed as mg of catechin equivalent (CE)/g of dried extract.

2.4.3. Estimation of Total Alkaloid Content (TAC). The TAC of the extract and fractions from S. japonica was determined by the UV-Spectrophotometric method as reported by Ajanal et al. (2012) [20]. The extract/fraction was dissolved in $2 \mathrm{~N} \mathrm{HCl}$ and filtered. Then $1 \mathrm{~mL}$ of this solution was transferred into a separating funnel, to which $5 \mathrm{~mL}$ of bromocresol blue solution and $5 \mathrm{~mL}$ of phosphate buffer $(\mathrm{pH}$ 4.7) were added. The mixture was shaken, and the complex formed was partitioned with chloroform. The fractions were collected in a volumetric flask and diluted to $10 \mathrm{~mL}$ with chloroform. The absorbance of the complex in chloroform was measured by a spectrophotometer at $470 \mathrm{~nm}$. The result was calculated from the standard curve of atropine and expressed as $\mathrm{mg}$ of atropine equivalent $(\mathrm{AE}) / \mathrm{g}$ of dried extract.

\subsection{Study of In Vitro Activities}

2.5.1. Anticholinesterase Activity Tests. The cholinesterase inhibitory activity was assessed by the spectrophotometric method of Ellman et al. [21]. AChE from mice brain homogenate and $\mathrm{BuChE}$ from human blood was prepared by the procedure described earlier [17]. In brief, brain tissues were collected from mice, homogenized in $50 \mathrm{mM}$ Tris- $\mathrm{HCl}$ ( $\mathrm{pH} 7.4$ ) containing $1.0 \mathrm{M} \mathrm{NaCl}$ and $50 \mathrm{mM} \mathrm{MgCl}_{2}$ and then centrifuged at $10,000 \mathrm{rpm}$ for 20 minutes at $4^{\circ} \mathrm{C}$ to yield the crude AChE. To prepare the BuChE enzyme, human blood was collected in EDTA $(1 \mathrm{mg} / \mathrm{mL})$ treated test tube from an anonymous healthy male subject (24 years) at the Rajshahi University Medical Center, Rajshahi, Bangladesh, and centrifuged at $4000 \mathrm{rpm}$ for 15 minutes at $4^{\circ} \mathrm{C}$. The resulting plasma was used as the source of the BuChE enzyme. Acetylthiocholine iodide (ATCI) and S-butyrylthiocholine iodide (BTCI) were employed as substrates for AChE and BuChE enzymes, respectively. Hydrolysis of ATCI/BTCI by cholinesterase was monitored spectrophotometrically. $200 \mu \mathrm{L}$ of enzyme solution was mixed with $500 \mu \mathrm{L}$ of the test sample and kept for 20 minutes at $37^{\circ} \mathrm{C}$. Just after adding Ellman's reaction mixture $(3.5 \mathrm{~mL} ; 0.5 \mathrm{mM}$ acetylthiocholine

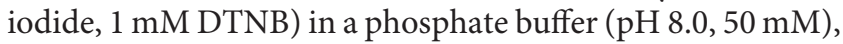
absorbance was recorded at $405 \mathrm{~nm}$ continuously for 5 minutes at 1 minute interval. A blank reaction was estimated by taking saline in place of the enzyme and a control reaction was also assessed by substituting the inhibitor with saline. Donepezil was used as a reference standard for AChE and galantamine for BuChE. The following formula was used to calculate the percentage inhibition of cholinesterase enzyme activity:

$\%$ enzyme inhibition $=\frac{\left(\Delta A_{\text {control }}-\Delta A_{\text {sample }}\right)}{\Delta A_{\text {control }}} \times 100 \%$,

where $\Delta A_{\text {control }}$ represents the change in absorbance per minute for control reaction; $\Delta A_{\text {sample }}$ represents the change in absorbance per minute for test sample reactions.
2.5.2. Inhibition Kinetics of Cholinesterase Enzymes. The kinetic modes of $\mathrm{AChE}$ and $\mathrm{BuChE}$ inhibition by $\mathrm{CHF}$ were determined by preparing a range of $\mathrm{CHF}$ (inhibitor) concentrations $(100,200$, and $400 \mu \mathrm{g} / \mathrm{mL})$ in which the concentration of the substrate (ATCI/BTCI) was varied $(1.4,0.7$, $0.35,0.175$ and $0.0875 \mathrm{mM}$ ). With different concentrations (S) of the substrate (ATCI/BTCI), the velocity of the enzyme inhibition was different. Each assay was carried out three times. Lineweaver-Burk graph was plotted from $\mathrm{S}^{-1}$ vs. $\mathrm{V}^{-1}$ to determine the type of inhibition [22]. From these data, $V_{\max }$ (maximum reaction velocity) and $K_{\mathrm{m}}$ (dissociation constant) were calculated.

2.5.3. Antioxidant Activity Tests. The antioxidant potential of the extract and fractions from S. japonica was tested by evaluating their DPPH (1, 1-diphenyl-2-picrylhydrazyl) free radical and hydroxyl radical scavenging activity, iron reducing power, lipid peroxidation inhibition, and total antioxidant capacity.

DPPH (1, 1-Diphenyl-2-picrylhydrazyl) Free Radical Scavenging Assay. The DPPH free radical scavenging activity of the extract and fractions from S. japonica was determined following the method described by Braca et al. (2001) [23]. The extract or standard at different concentrations (3.125, $6.25,12.5,25,50$, and $100 \mu \mathrm{g} / \mathrm{mL}$ ) was taken in test tubes, to which $3 \mathrm{~mL}$ of methanolic solution of DPPH $(0.135 \mathrm{mM})$ was added. The tube was left at room temperature for 30 minutes in a dark place. The absorbance of the solution was measured at $517 \mathrm{~nm}$ using a spectrophotometer against a blank. A control reaction was also prepared with a methanolic solution of DPPH and other reagents instead of plant extract or standard solution. The percent (\%) of DPPH radical scavenging was calculated from the following equation:

$$
\% \text { scavenging }=\frac{\left(A_{0}-A_{1}\right)}{A_{0}} \times 100 \% .
$$

where $A_{0}$ is the absorbance of the control; $A_{1}$ is the absorbance of the extract/standard.

Hydroxyl Radical Scavenging Assay. Hydroxyl radical scavenging activity of the extract/fractions from $S$. japonica was determined following the method described by Halliwell and Gutteridge (1987) [24] with slight modification. In brief, a reaction mixture was prepared by taking $100 \mu \mathrm{M} \mathrm{FeCl}$, $2.8 \mathrm{mM}$ 2-deoxy-D-ribose, $20 \mathrm{mM}$ potassium dihydrogen phosphate buffer (pH 7.4), $100 \mu \mathrm{M}$ EDTA, $1.0 \mathrm{mM}$ hydrogen peroxide, and $100 \mu \mathrm{M}$ ascorbic acid. To $1 \mathrm{ml}$ of the reaction mixture, sample (extract/standard) solution at different concentrations $(12.5,25,50,100$, and $200 \mu \mathrm{g} / \mathrm{mL})$ was added and incubated for 1 hour at $37{ }^{\circ} \mathrm{C}$. Afterward, $1 \mathrm{~mL}$ of the reaction mixture was added to $1.0 \mathrm{~mL}$ of $10 \%$ TCA and $1.0 \mathrm{~mL}$ of $1 \% \mathrm{TBA}$ (in $0.1 \mathrm{M} \mathrm{NaOH}$ containing $0.025 \% \mathrm{BHA}$ ) and heated at $100^{\circ} \mathrm{C}$ for 20 minutes. The absorbance of the solution was measured spectrophotometrically at $532 \mathrm{~nm}$ against a blank solution. A control solution was prepared in the same way where all the reagents except the sample were present. The percent scavenging potential of samples was calculated from the following equation: 


$$
\% \text { scavenging }=\frac{\left(A_{0}-A_{1}\right)}{A_{0}} \times 100 \% .
$$

where $A_{0}$ is the absorbance of the control solution and $A_{1}$ is the absorbance of the extract samples and reference standard. All the tests were performed in triplicate.

Ferric Reducing Power Assay. The iron reducing power of the extract/fractions of $S$. japonica was evaluated by the method developed by Oyaizu (1986) [25]. A $2.5 \mathrm{~mL}$ sample/standard solution at different concentrations $(12.5,25,50$, and $100 \mu \mathrm{g} /$ $\mathrm{mL}$ ) was added to $2.5 \mathrm{~mL}$ phosphate buffer $(200 \mathrm{mM}, \mathrm{pH} 6.6)$ and $2.5 \mathrm{~mL}$ of $1 \%$ potassium ferricyanide and incubated at $50^{\circ} \mathrm{C}$ in a water bath for 20 minutes. After cooling, $2.5 \mathrm{~mL}$ of $10 \%$ trichloroacetic acid (TCA) was added to the mixture and centrifuged at $3000 \mathrm{rpm}$ for $10 \mathrm{~min}$. Then $5 \mathrm{~mL}$ supernatant was mixed with $5 \mathrm{~mL}$ of distilled water and $1 \mathrm{~mL}$ of ferric chloride and incubated at $37^{\circ} \mathrm{C}$ for 10 minutes. The absorbance of the mixture was measured at $700 \mathrm{~nm}$ against a blank solution.

Lipid Peroxidation Inhibition Assay. The inhibition of lipid peroxidation assay of the extract/fraction of S. japonica was determined according to the method described by Liu et al. (2000) with a slight modification [26]. Brain lipid was prepared from mouse brain through homogenization of brain in $50 \mathrm{mM}$ phosphate buffer ( $\mathrm{pH} 7.4$ ) containing $0.15 \mathrm{M}$ $\mathrm{KCl}$ and centrifugation at $10000 \mathrm{~g}$ for $15 \mathrm{~min}$ at $4^{\circ} \mathrm{C}$. Sample/ standard solutions at different concentrations $(12.5,25,50$, 100 , and $200 \mu \mathrm{g} / \mathrm{mL}$ ) were mixed with $500 \mu \mathrm{L}$ of brain lipid and $0.2 \mathrm{mM} \mathrm{FeCl}_{3}$ and incubated at $37^{\circ} \mathrm{C}$ for 30 minutes. After adding $2 \mathrm{ml}$ of ice-cold $\mathrm{HCl}(0.25 \mathrm{~N})$ containing $15 \%$ trichloroacetic acid (TCA), $0.38 \%$ TBA, and $0.5 \%$ BHT, the mixtures were heated at $80^{\circ} \mathrm{C}$ for 1 hour and centrifuged at $3000 \mathrm{rpm}$ for 10 minutes to remove precipitated proteins. The solution was measured colorimetrically at $532 \mathrm{~nm}$ against a blank solution. A control solution was prepared in the same way that contained all the reagents except the sample. The percent inhibition of lipid peroxidation was calculated using the following formula:

$$
\% \text { inhibition }=\frac{\left(A_{0}-A_{1}\right)}{A_{0}} \times 100 \% .
$$

where $A_{0}$ is the absorbance of the control solution and $A_{1}$ is the absorbance of the sample solution.

Total Antioxidant Capacity Assay. The total antioxidant capacity of the extract/fraction of S. japonica was determined by the method of Prieto et al. (1999) with some modifications [27]. Initially, $0.5 \mathrm{~mL}$ sample at different concentrations was added to $3 \mathrm{~mL}$ of the reaction mixture $(0.6 \mathrm{M}$ sulphuric acid, $28 \mathrm{mM}$ sodium phosphate and $4 \mathrm{mM}$ ammonium molybdate) in the test tube and heated at $95^{\circ} \mathrm{C}$ for 90 minutes in a water bath. After cooling, the absorbance of the reaction solution was measured at $695 \mathrm{~nm}$ against a blank.

2.6. In Vivo Study. The in vivo experiments were performed to assess the effects of CHF obtained from S. japonica stems employing a scopolamine-induced mouse model of memory impairment.
2.6.1. Experimental Animals. Swiss Albino mice (male, 6 weeks) were collected from the International Center for Diarrhoeal Disease Research, Bangladesh (ICDDR, B) and kept in congenial conditions for seven days for the adjustment and suitable food and water were provided ad libitum according to the formula given by ICDDR, B. The experimental protocol was approved (Ethical clearance number: 103) by the Institutional Animal, Medical Ethics, Biosafety, and Biosecurity Committee (IAMBBC) at the Institute of Biological Science, University of Rajshahi. The behavioral assessments were usually conducted in the first half of the daytime.

\subsubsection{Plant Material and Treatment Schedule.} Memory-enhancing potential of CHF was tested in scopolamine-induced memory-impaired mice using donepezil as a reference standard. All the drugs and test samples were dissolved in 6\% dimethyl sulfoxide (DMSO)/94\% water and injected intraperitoneally $(4 \mathrm{~mL} / \mathrm{kg}$ ) into the mice. Thirty-six healthy mice were randomly selected and divided into six groups as follows:

Group I: normal vehicle group (NVG), which received only DMSO $(4 \mathrm{~mL} / \mathrm{kg})$.

Group II: scopolamine group (SCO), which received scopolamine $(1 \mathrm{mg} / \mathrm{kg})$.

Group III: donepezil group (DON), which received donepezil (5 mg/kg) [28] and scopolamine $(1 \mathrm{mg} / \mathrm{kg})$.

Group IV-VI: test groups (CHF 100, 50, and 25), which received one of the three doses $(100,50$, and $25 \mathrm{mg} / \mathrm{kg})$ of the S. japonica CHF fraction and scopolamine $(1 \mathrm{mg} /$ $\mathrm{kg})$.

The experimental schedule is shown in Figure 1. Donepezil and CHF extract were administered to the mice of Groups III-VI during test days (Days 12-15) one hour before scopolamine injection. A resting period of thirty minutes was maintained after scopolamine administration to the mice before initiating behavioral assessments.

2.6.3. Spatial Memory and Learning Test in Morris Water Maze. Effects of CHF on spatial memory and learning were investigated by employing the widely accepted Morris water maze (MWM) task in the scopolamine-induced mouse model of memory impairment $[29,30]$. The components of the MWM include a large round black water tank (radius $=75 \mathrm{~cm}$, height $=60 \mathrm{~cm}$ ) and a $28 \mathrm{~cm}$ black platform. The water is maintained at room temperature with the platform constantly placed $1 \mathrm{~cm}$ under the water surface in the center of the northeast (NE) quadrant of the tank. After an acclimatization period of seven days, all the mice were trained for four consecutive days in the MWM and then tested for their spatial memory and learning for the next four days (Figure 1). During the training period (Days 8-11) of the mice, the highest 60 seconds was allotted for finding the concealed platform and 20 seconds to rest on it. Two trials were conducted daily for all mice. Throughout the test period (Days 12-15), the mean latency time (MLT) of all 


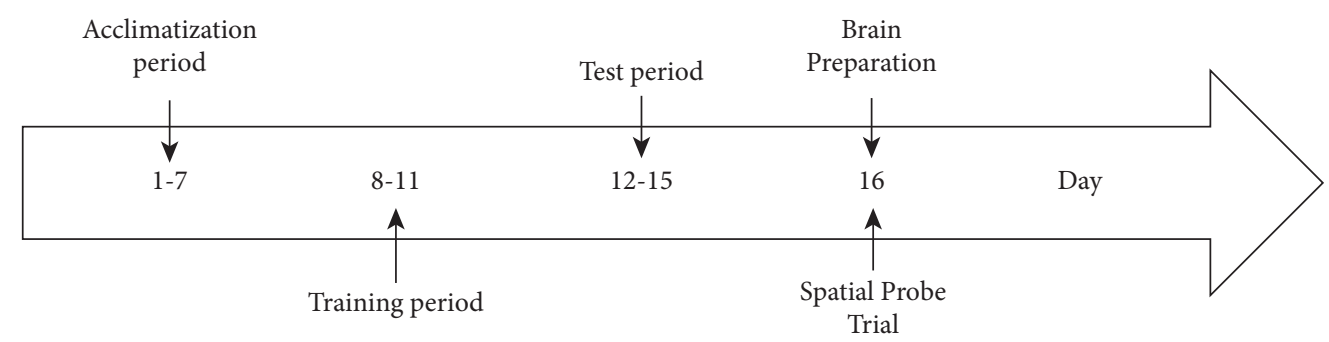

FIgURE 1: A general overview of the animal study timeline.

mice for each day was calculated from the two trials, where a substantial reduction in MLT indicates successful learning. On the next day (Day 16), the mice were made to go through a probe trial where the platform remained absent with an objective to test the spatial memory of the location of the platform. The mice were allowed to browse throughout the tank for 60 seconds and the time spent in the NE quadrant (last location of the platform) was noted. Higher time resided in the NE quadrant represents better performance.

2.6.4. Biochemical Assays. Surgical decapitation was performed in mice on the $16^{\text {th }}$ day of the animal study program after being anesthetized with sodium pentobarbital $(30 \mathrm{mg}$ / $\mathrm{kg}$; intraperitoneal injection). The mice brains were separated and homogenized in the extraction buffer $(50 \mathrm{mM}$ Tris- $\mathrm{HCl}$ buffer containing $1 \%$ Triton $\mathrm{X}-100$ ) by a homogenizer. The resulting mice brain homogenate $(\mathrm{MBH})$ was centrifuged at $5000 \mathrm{rpm}$ for 20 minutes to obtain the supernatant and stored in the fridge for further experiments.

Estimation of Protein Concentration. The protein concentration of brain homogenate was estimated by the Lowry et al. (1951) procedure employing bovine serum albumin calibration curve [31]. The results were calculated as $\mathrm{mg}$ of protein present per $\mathrm{mL}$ of mice brain homogenate $(\mathrm{MBH})$.

Determination of Brain AChE Activity. The AChE enzyme activity in mice brain homogenate was determined by Ellman et al. method (1961) as described earlier [21]. $200 \mu \mathrm{L}$ mice brain homogenate $(\mathrm{MBH})$ was added to $2.2 \mathrm{~mL} 50 \mathrm{mM}$ Tris- $\mathrm{HCl}$ buffer and $200 \mu \mathrm{L}$ DTNB $(15 \mathrm{mM})$ and incubated for 15 minutes at room temperature. Then a change in absorbance per minute was noted at $412 \mathrm{~nm}$ immediately after adding $400 \mu \mathrm{L}$ acetylthiocholine iodide $(3.75 \mathrm{mM})$ to the mixture. The specific enzyme activity was expressed as $\mathrm{mU} / \mathrm{mg}$ of protein in $\mathrm{MBH}$.

Brain Reduced Glutathione ( $r G S H)$ Level. rGSH level was estimated in $\mathrm{MBH}$ according to the method of Ellman et al. (1959) [32]. $0.25 \mathrm{ml} \mathrm{MBH}$ was mixed with $1.25 \mathrm{ml}$ phosphate buffer (0.1 M, pH 7.2) and $1.5 \mathrm{ml}$ distilled water. Then $20 \mu \mathrm{L}$ DTNB was added to the mixture and incubated for 1 hour at room temperature. The absorbance of the mixture was read at $412 \mathrm{~nm}$. The amount of reduced glutathione was calculated with the Beer-Lambert formula using the extinction coefficient value of $13,600 \mathrm{M}^{-1} \mathrm{~cm}^{-1}$. The results are expressed as $\mu \mathrm{mol}$ rGSH per mg of protein in $\mathrm{MBH}$.
Brain Malondialdehyde (MDA) Level. MDA level in $\mathrm{MBH}$ was determined by the method described by Esterbauer and Cheeseman (1990) [33]. $0.25 \mathrm{ml} \mathrm{MBH}$ was mixed with $2.75 \mathrm{ml}$ trichloroacetic acid (TCA, 10\% w/v) and centrifuged to discard the protein pellets. The resulting supernatant was mixed with $3 \mathrm{ml} \mathrm{TBA}(0.67 \% \mathrm{w} / \mathrm{v})$ and heated at $100{ }^{\circ} \mathrm{C}$ for 10 minutes in a water bath. The absorbance of the solution was measured at $532 \mathrm{~nm}$. The amount of MDA was calculated using Beer-Lambert's formula with the extinction coefficient value of $1.56 \times 10^{5} \mathrm{M}^{-1} \mathrm{~cm}^{-1}$. The result is expressed as nmol MDA per mg protein in $\mathrm{MBH}$.

Brain Superoxide Dismutase (SOD) Activity. SOD activity was determined by the method described earlier [34], based on the ability of the enzyme to inhibit the autoxidation of pyrogallol. $50 \mu \mathrm{L} \mathrm{MBH}$ was added to $1 \mathrm{ml}$ Tris-EDTA buffer and then the change in absorbance per minute was noted immediately after adding $1 \mathrm{ml}$ pyrogallol at $420 \mathrm{~nm}$ against Tris-EDTA buffer as blank. On the other hand, for the control reaction, the $\mathrm{MBH}$ was substituted with distilled water. SOD activities are expressed as units/mg of protein in $\mathrm{MBH}$. One unit of SOD activity is defined as the amount of enzyme required to cause $50 \%$ inhibition of pyrogallol autoxidation [35].

Brain Catalase (CAT) Activity. CAT activity was measured by the method of Aebi et al. (1974) [36]. 0.1 mL MBH was added to the cuvette containing $1.9 \mathrm{~mL}$ of $50 \mathrm{mM}$ phosphate buffer ( $\mathrm{pH}$ 7.0). The reaction was started by adding $1.0 \mathrm{~mL}$ of freshly prepared $30 \mathrm{mM} \mathrm{H}_{2} \mathrm{O}_{2}$. The rate of decomposition of $\mathrm{H}_{2} \mathrm{O}_{2}$ by catalase was measured spectrophotometrically from changes in absorbance at $240 \mathrm{~nm}$. A control reaction was also devised with the $\mathrm{MBH}$ replaced with $50 \mathrm{mM}$ phosphate buffer ( $\mathrm{pH}$ 7.0). The results were calculated using the molar extinction coefficient of $43.6 \mathrm{M}^{-1} \mathrm{~cm}^{-1}$ for hydrogen peroxide and expressed as units/mg protein in $\mathrm{MBH}$.

2.7. Characterization of the CHF. Thin layer chromatographic (TLC) analysis of CHF was performed on TLC Silica gel $60 \mathrm{~F}_{254}$ Aluminum sheets (MERCK, Germany) with n-hexane:chloroform:methanol $(4: 4: 2)$ as the mobile phase. UV spectra of the CHF were recorded in methanol solution using the BECKMAN double beam spectrophotometer in the Central Science Laboratory, University of Rajshahi, and the data are given in $\lambda_{\max }$. IR spectra of the CHF were recorded using the PERKIN ELMER 1600 FTIR spectrophotometer in the Central Science Laboratory, University of Rajshahi, and the data are given in $\mathrm{cm}^{-1}$. 
2.8. Statistical Analysis. All output data were expressed as mean \pm SD. Graph Pad Prism (version 8.0.1), SPSS (IBM SPSS Statistics 21.0), and Microsoft Excel 2010 were used for the statistical and graphical evaluations. The escape latencies in the Morris water maze task were analyzed by two-way ANOVA. The probe trial data in the water maze, biochemical parameters, and the data from in vitro assays were analyzed by one-way ANOVA. A $p$-value of $<0.05$ was considered as significant artistically. $\mathrm{IC}_{50}$ values of different fractions/extractives were calculated using nonlinear regression (Dose-Response--Inhibition equation; $\log _{10}$ (inhibitor) vs. normalized response--variable slope) in Graph Pad Prism-8.0.1. A correlation study was performed using the Pearson correlation test.

\section{Results}

3.1. Phytochemical Analyses. Qualitative analyses of CME of $S$. japonica and its fractions indicated the presence of phenolics, flavonoids, alkaloids, saponins, steroids, and glycosides. Interestingly, all these phytoconstituents were found in the different fractions, but phenolics, flavonoids, and alkaloids were high in the CHF (Supplementary Table S1). Quantitative investigations revealed the highest content of phenolics $(313.06 \pm 2.76 \mathrm{mg} \mathrm{GAE} / \mathrm{g}$ dried extract), flavonoids (167.25 $\pm 1.34 \mathrm{mg} \mathrm{CE} / \mathrm{g}$ dried extract), and alkaloids $(216.97 \pm 4.63 \mathrm{mg} \mathrm{AE} / \mathrm{g}$ dried extract) in the $\mathrm{CHF}$ followed by EAF, AQF, and PEF (Table 1).

TPC, total phenolic content; TFC, total flavonoid content; TAC, total alkaloid content; GAE, gallic acid equivalent; $\mathrm{CE}$, catechin equivalent; $\mathrm{AE}$, atropine equivalent; $\mathrm{CME}$, crude methanolic extract, $\mathrm{CHF}$, chloroform fraction; $\mathrm{EAF}$, ethyl acetate fraction; $\mathrm{AQF}$, aqueous fraction; $\mathrm{PEF}$, petroleum ether fraction; values are expressed as mean \pm standard deviation.

\subsection{In Vitro Anticholinesterase Activity}

3.2.1. Anti-AChE and Anti-BuChE Activity. The inhibitory activities of the CME and its fractions against AChE and BuChE are presented in Figure 2. All the extract and fractions exhibited a dose-dependent inhibition of AChE and BuChE enzymes. The highest activity was found in the $\mathrm{CHF}$ followed by EAF, $\mathrm{AQF}$, and $\mathrm{PEF}$. The $\mathrm{IC}_{50}$ values of $\mathrm{CHF}$ were $40.06 \pm 0.79 \mu \mathrm{g} / \mathrm{mL}$ and $18.78 \pm 0.69 \mu \mathrm{g} / \mathrm{mL}$ for $\mathrm{AChE}$ and $\mathrm{BuChE}$, respectively, suggesting that the $\mathrm{CHF}$ has greater inhibitory activity against BuChE than that of AChE. The anti-ChE activity of CHF was found to be good when compared with the strong cholinesterase inhibitor galantamine (for anti-BuChE) or donepezil (for anti-AChE) used in this study.

3.2.2. Analysis of Mode of Inhibition. Since CHF showed strong inhibition against both the AChE and BuChE, we investigated further to determine the modes of enzyme inhibition of this fraction using Lineweaver-Burke plots. Plots of AChE and BuChE inhibition by $\mathrm{CHF}$ were linear and intersected at a point on $X$-axis (Figure 3 ). These results indicated that $\mathrm{CHF}$ is a noncompetitive inhibitor for both $\mathrm{AChE}$ and BuChE.

3.3. In Vitro Antioxidant Activity. Antioxidant activity of the CME and its fractions were assessed by several in vitro assays such as DPPH radical scavenging and hydroxyl radical scavenging, ferric reducing power, total antioxidant activity, and lipid peroxidation inhibition assay, and the results have been presented in Figure 4. The results of DPPH and hydroxyl radical scavenging revealed that all the extract and fractions have scavenging activity and the activity was found to be dose-dependent. The highest activity was found in $\mathrm{CHF}$ followed by EAF, AQF, and PEF. The $\mathrm{IC}_{50}$ values of $\mathrm{CHF}$ were $5.01 \mu \mathrm{g} / \mathrm{mL}$ and $17.12 \mu \mathrm{g} / \mathrm{mL}$ for DPPH and hydroxyl radical scavenging, respectively. Further, the activity of the $\mathrm{CHF}$ appeared to be good when compared with the strong antioxidant catechin, which showed an $\mathrm{IC}_{50}$ value of $3.03 \mu \mathrm{g} /$ $\mathrm{mL}$ and $9.00 \mu \mathrm{g} / \mathrm{mL}$ for DRS and HRS, respectively.

In ferric reducing power assay and total antioxidant capacity assay, $\mathrm{CHF}$ also exhibited the highest antioxidant activity, followed by EAF, AQF, and PEF. The absorbance values of $\mathrm{CHF}$ at $100 \mu \mathrm{g} / \mathrm{mL}$ concentration were 2.49 and 1.85 for ferric reducing power and total antioxidant capacity, respectively.

In lipid peroxidation inhibition assay, peroxidation of lipid was induced in the brain homogenate by hydroxyl radical generated in Fenton reaction and the ability of the $\mathrm{CME}$ and its fractions to inhibit the peroxidation of lipid was then assessed. The result is shown in Figure 4(e). As expected, CHF exhibited the highest activity among the fractions with an $\mathrm{IC}_{50}$ of $33.42 \mu \mathrm{g} / \mathrm{mL}$ and PEF, the lowest with an $\mathrm{IC}_{50}$ of $248.20 \mu \mathrm{g} / \mathrm{mL}$. The overall results indicated the superior antioxidant potential of $\mathrm{CHF}$ of S. japonica.

3.4. Correlation between Phytochemicals and Anticholinesterase and Antioxidant Activity. The bioactivity of a plant is mediated by its phytochemicals. Since the CME of S. japonica and its fractions were found to contain a considerable amount of polyphenolics and alkaloids and exhibited potent antcholinesterase and antioxidant activities, we tested the correlations between these phytochemical contents and cholinesterase inhibitory and antioxidant activity and the results are shown in Table 2. A significant correlation $(P<0.05)$ was observed between TAC and BuChE inhibition $(r=0.961)$, hydroxyl radical scavenging $(r=0.979)$, and lipid peroxidation inhibition $(r=0.939)$. Likewise, the correlation between TPC and AChE inhibition $(r=0.920)$, DPPH radical scavenging $(r=0.943)$, lipid peroxidation inhibition $(r=0.928)$, ferric reducing power $(r=0.971)$, and total antioxidant capacity $(r=0.963)$ was also found to be significant $(P<0.05)$. The TFC showed a significant association with DPPH radical scavenging $(r=0.929)$ and ferric reducing power $(r=0.931)$. These results suggested the involvement of alkaloids and polyphenolics in the inhibition of cholinesterase and antioxidant activity. 
TABLE 1: Quantitative phytochemical analysis of different extracts of S. japonica.

\begin{tabular}{lccc}
\hline Samples & TPC & TFC & TAC \\
& mg GAE/g dried extract & mg CE/g dried extract & $111.73 \pm 3.10$ \\
CME & $212.36 \pm 3.60$ & $90.47 \pm 2.27$ & $216.97 \pm 4.63$ \\
CHF & $313.06 \pm 2.76$ & $167.25 \pm 1.34$ & $129.19 \pm 2.65$ \\
EAF & $149.22 \pm 3.40$ & $134.99 \pm 1.62$ & $115.70 \pm 2.15$ \\
AQF & $61.94 \pm 3.18$ & $78.22 \pm 2.91$ & $13.63 \pm 2.62$ \\
PEF & $51.77 \pm 3.42$ & $71.76 \pm 1.62$ & mg AE/g dried extract \\
\hline
\end{tabular}

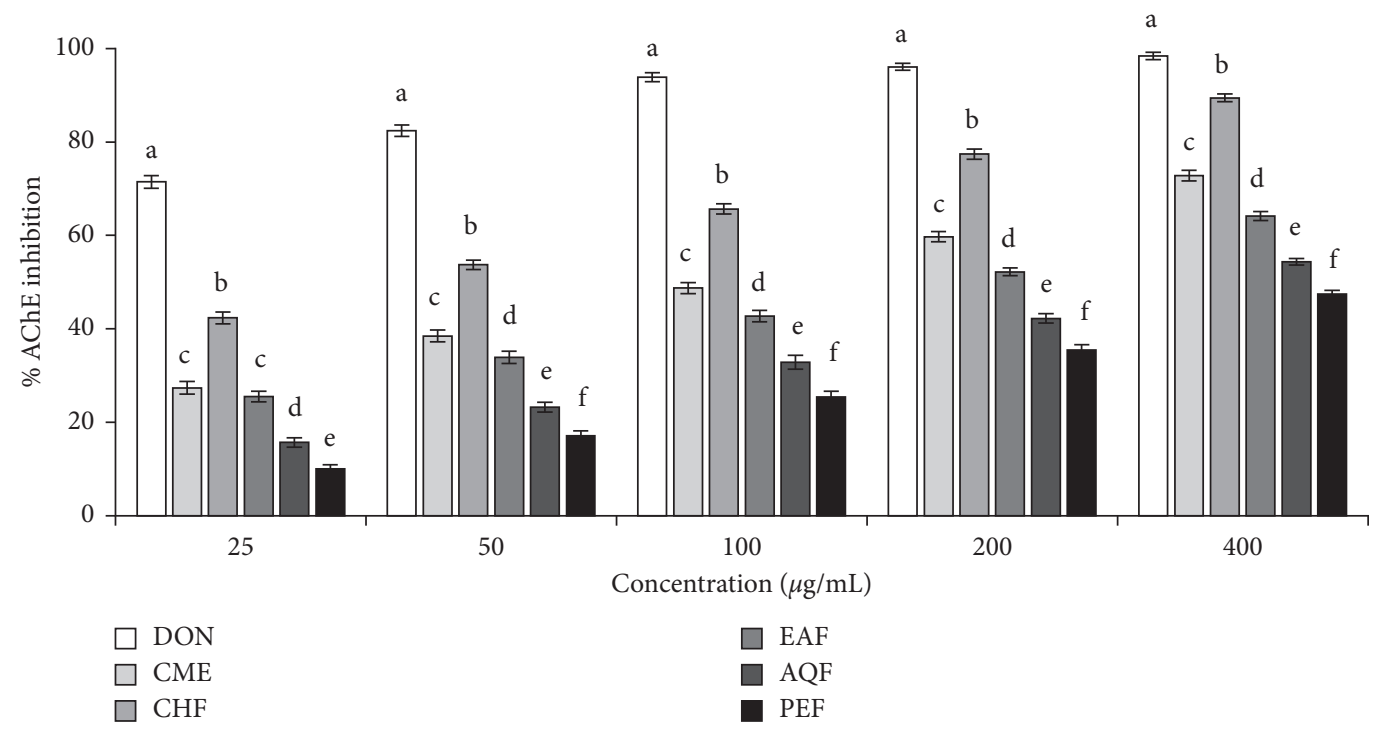

(a)

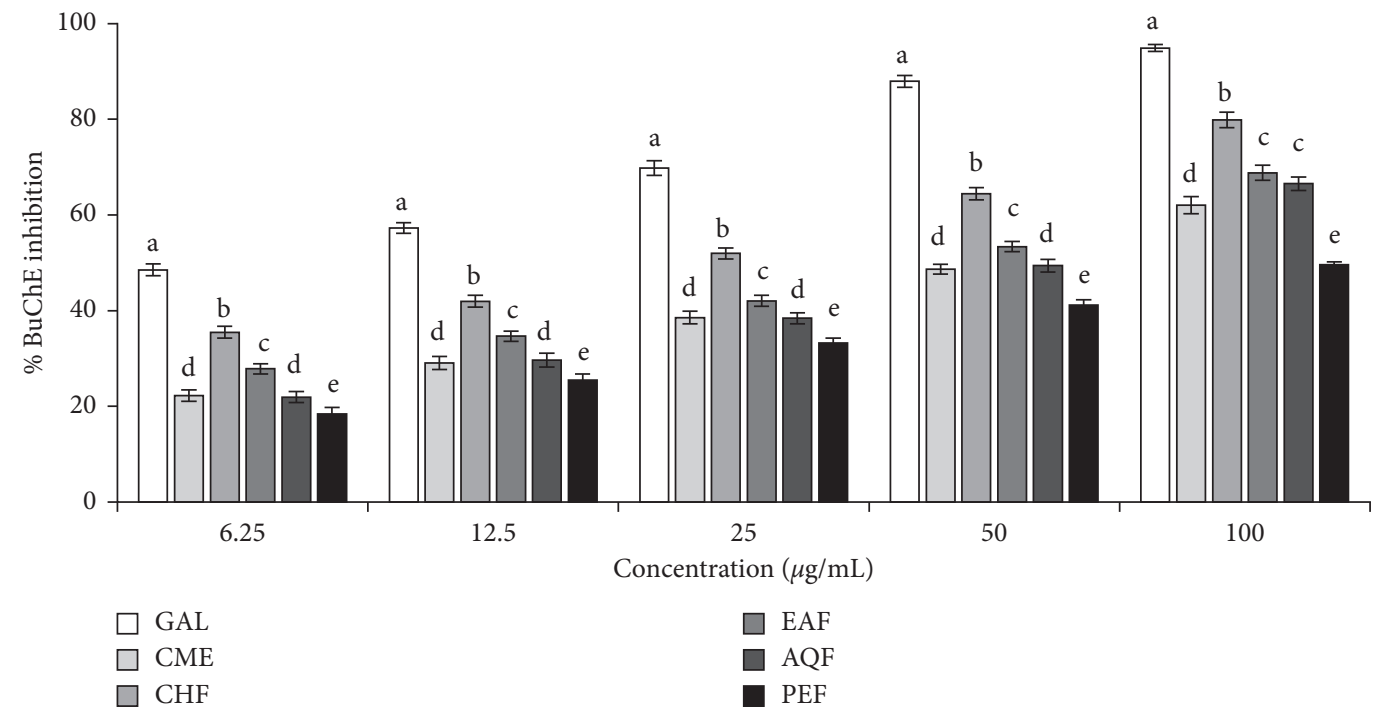

(b)

FIgURE 2: Anticholinesterase activity of the crude methanol extract of Sjaponica and its fractions. (a) AChE inhibitory activity. $\mathrm{IC}_{50}(\mu \mathrm{g} / \mathrm{mL})$ : DON, $5.21 \pm 0.18$; CME, 104.13 \pm 1.86; CHF, 40.06 \pm 0.79; EAF, 159.57 \pm 2.57 ; AQF, $308.57 \pm 2.27$; PEF, 453.17 \pm 4.28 . (b) BuChE inhibitory activity. $\mathrm{IC}_{50}(\mu \mathrm{g} / \mathrm{mL})$ : GAL, $7.91 \pm 0.35$; CME, 50.44 \pm 1.10 ; CHF, $18.78 \pm 0.69$; EAF, $35.30 \pm 0.92$; AQF, $44.73 \pm 1.40$; PEF, $100.08 \pm 2.12$. Results are expressed as mean $\pm \mathrm{SD}(n=3)$. Means with different letters $(\mathrm{a}-\mathrm{f})$ differ significantly $(P<0.05)$. CME, crude methanolic extract; $\mathrm{CHF}$, chloroform fraction; EAF, ethyl acetate fraction; $\mathrm{AQF}$, aqueous fraction; $\mathrm{PEF}$, petroleum ether fraction; AChE, acetylcholinesterase; BuChE, butyrylcholinesterase; DON, donepezil; GAL, galantamine. 


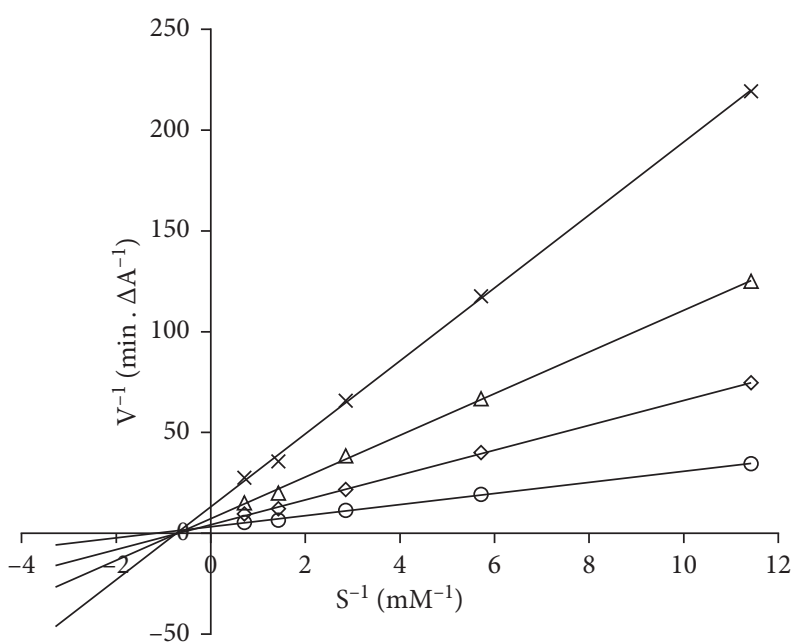

o Control

$\diamond \mathrm{CHF}-100 \mu \mathrm{g} / \mathrm{mL}$

$\Delta$ CHF- $200 \mu \mathrm{g} / \mathrm{mL}$

$\times$ CHF $-400 \mu \mathrm{g} / \mathrm{mL}$

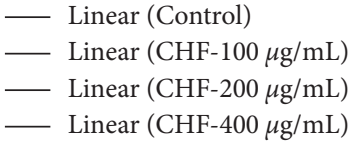

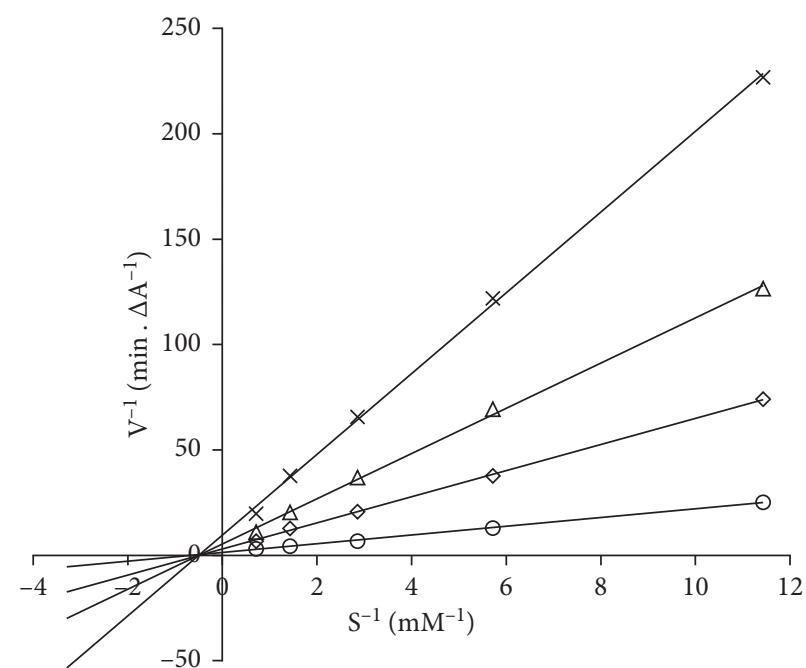

○ Control

$\diamond$ CHF $-100 \mu \mathrm{g} / \mathrm{mL}$

$\triangle$ CHF-200 $\mu \mathrm{g} / \mathrm{mL}$

$\times$ CHF- $400 \mu \mathrm{g} / \mathrm{mL}$

(a)

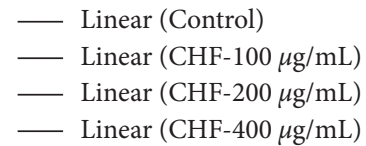

(b)

FIGURE 3: Lineweaver-Burk plot for inhibition of AChE (a) and BuChE (b) by different concentrations of CHF. Results represent the average values $(n=3)$

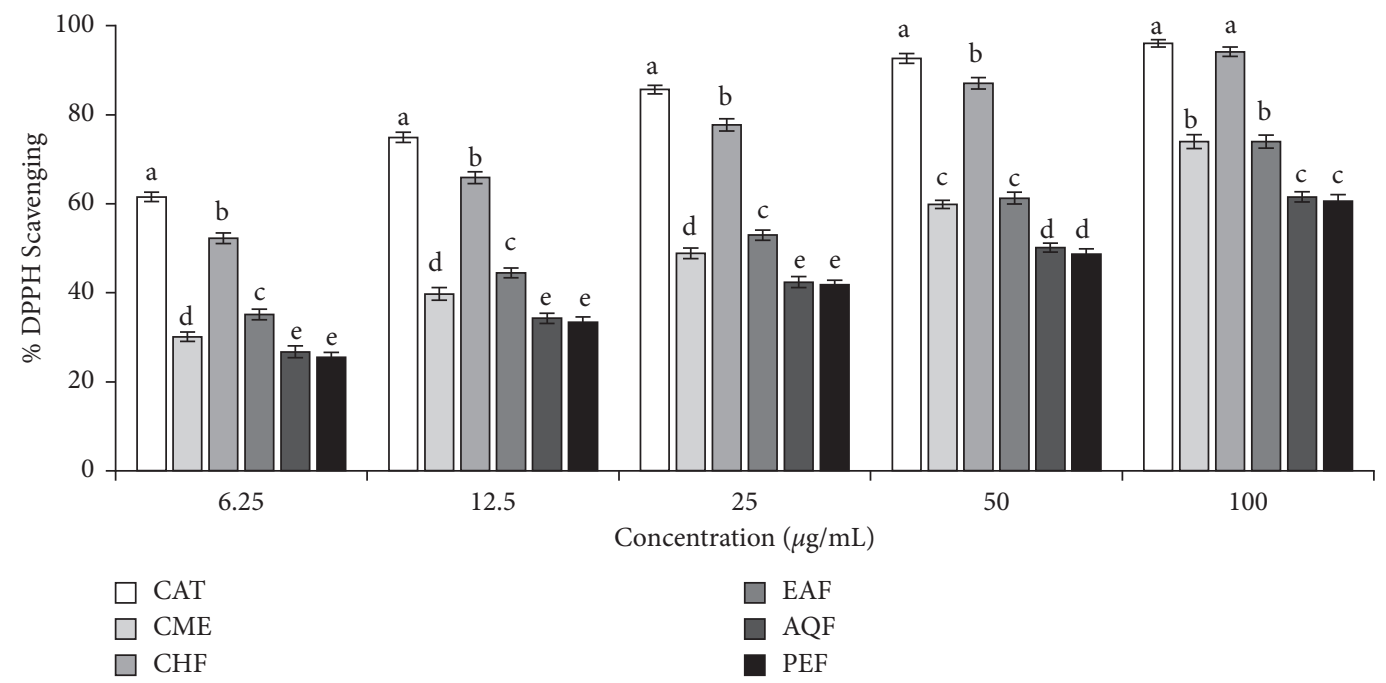

(a)

FIgURe 4: Continued. 


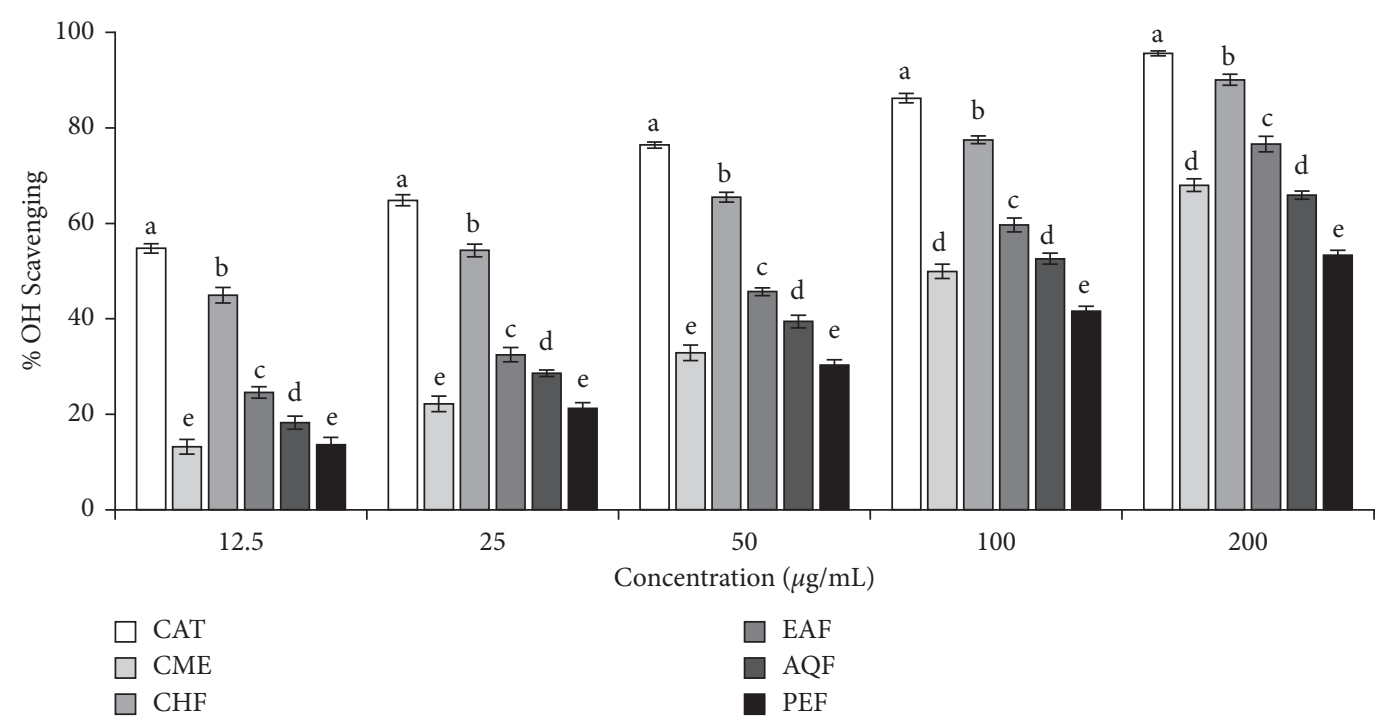

(b)
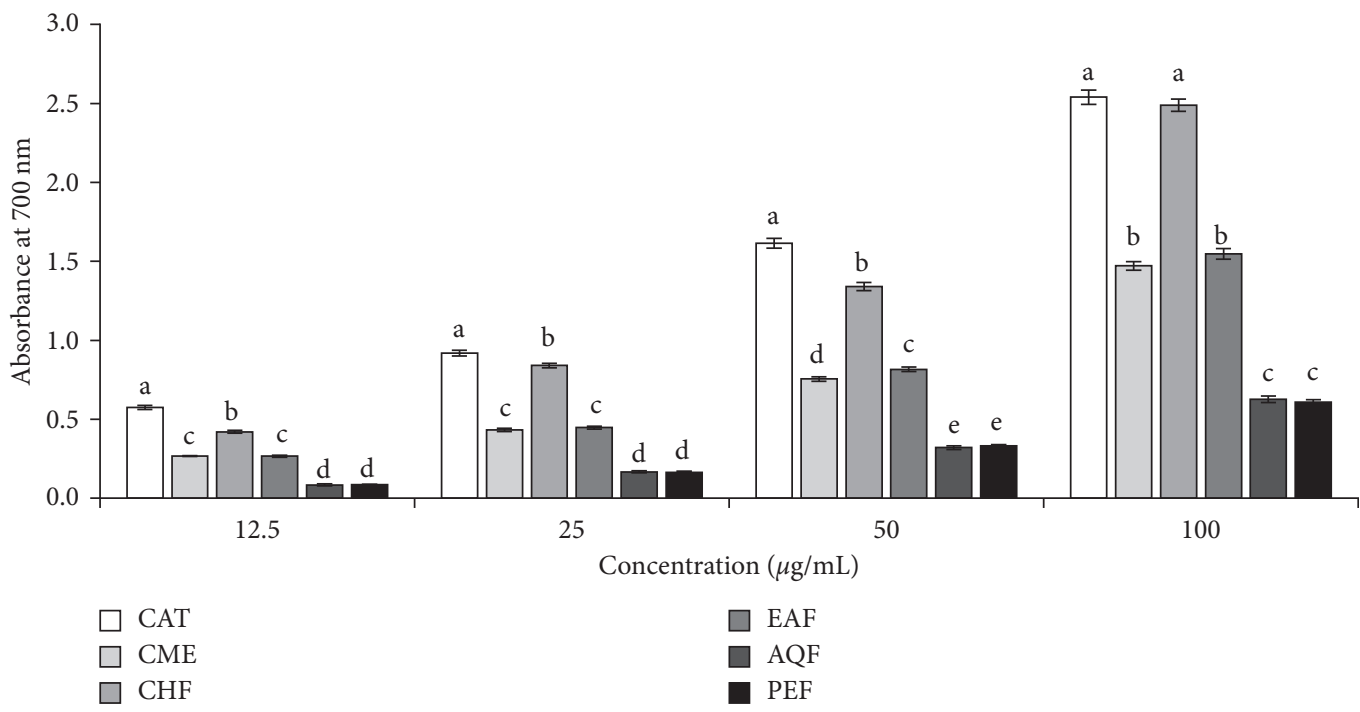

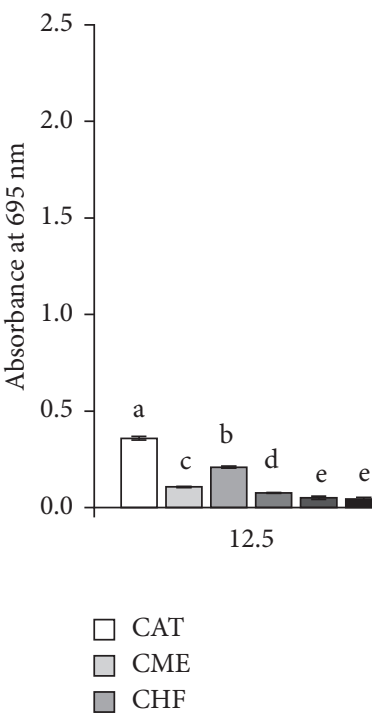

$\square \mathrm{EAF}$

$\square \mathrm{AQF}$

- $\mathrm{PEF}$

(c)

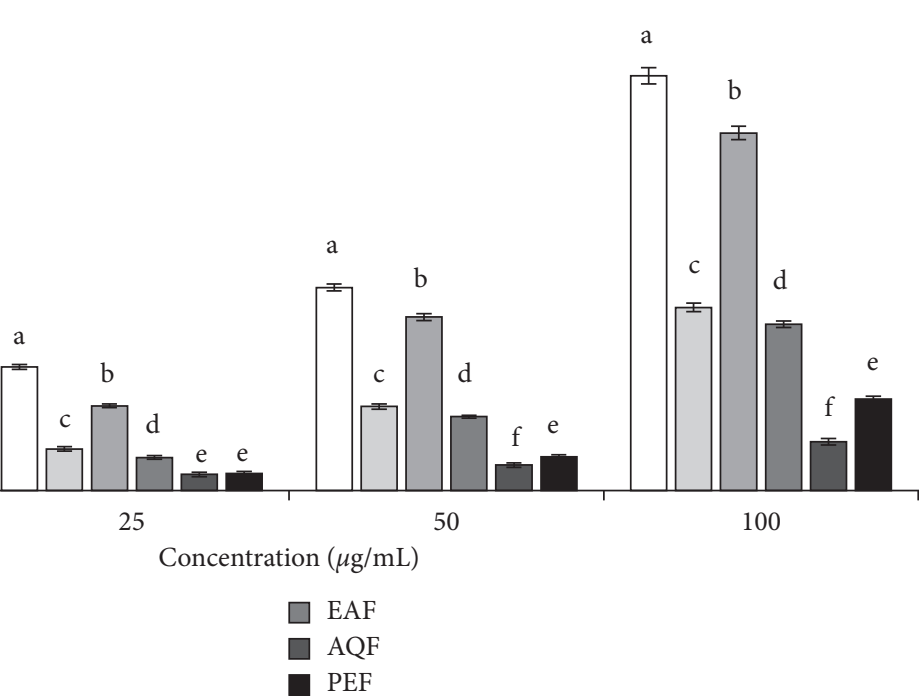

(d) 


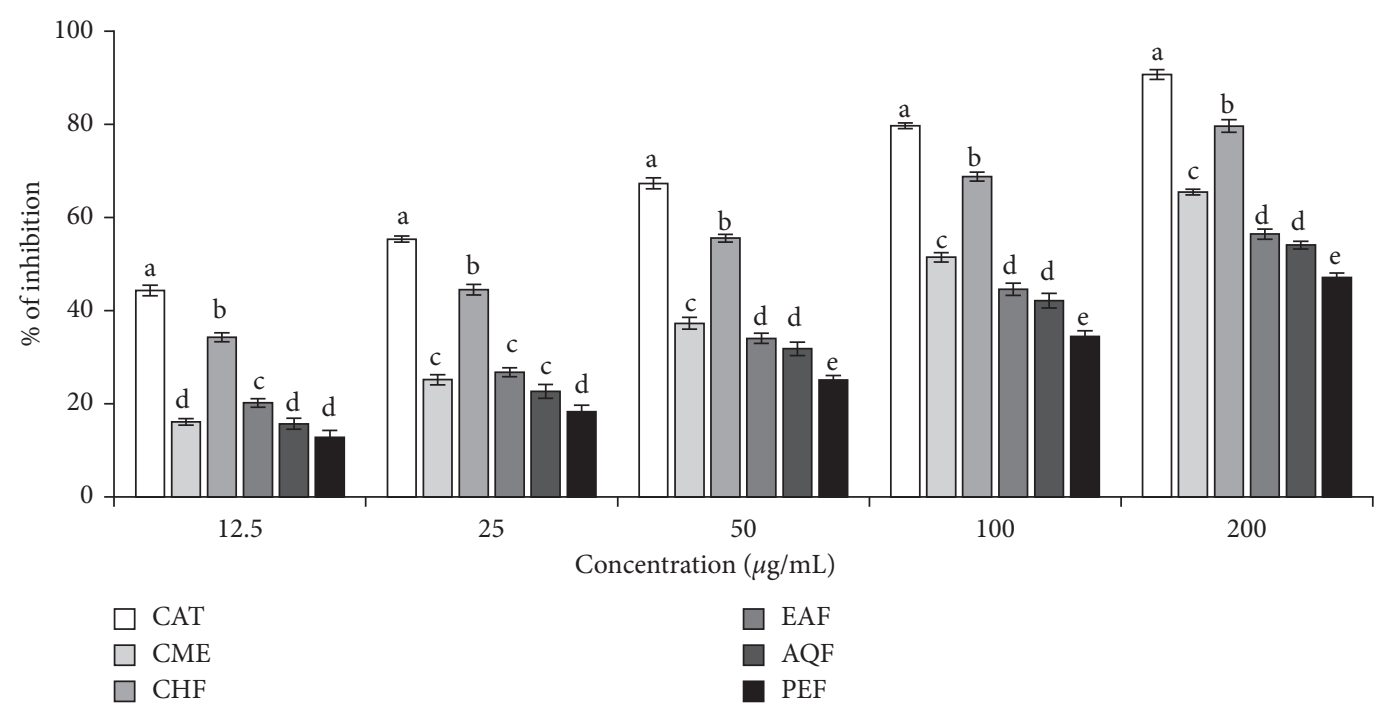

(e)

Figure 4: Antioxidant activity of CME of S japonica and its fractions. (a) DPPH radical scavenging activity. $\mathrm{IC}_{50}(\mu \mathrm{g} / \mathrm{mL})$ : CAT, $3.03 \pm 0.15$; CME, 24.12 \pm 1.00; CHF, $5.01 \pm 0.16$; EAF, $19.10 \pm 0.73$; AQF, $44.57 \pm 1.90$; PEF, $48.48 \pm 3.47$. (b) Hydroxyl radical scavenging activity. IC 50 ( $\mu \mathrm{g} / \mathrm{mL})$ : CAT, $9.00 \pm 0.34$; CME, 97.24 \pm 1.09 ; CHF, 17.12 \pm 0.23 ; EAF, $56.67 \pm 0.63$; AQF, $86.08 \pm 1.88$; PEF, 162.00 \pm 1.76 . (c) Ferric reducing power. At $100 \mu \mathrm{g} / \mathrm{mL}$ concentration, the absorbances are as follows: CAT, $2.539 \pm 0.045$; CME, $1.471 \pm 0.027$; CHF, 2.489 \pm 0.039 ; EAF, $1.548 \pm 0.033 ; \mathrm{AQF}, 0.627 \pm 0.020$; PEF, $0.609 \pm 0.014$. (d) Total antioxidant capacity. At $100 \mu \mathrm{g} / \mathrm{mL}$ concentration, the absorbances are as follows: CAT, $2.147 \pm 0.042$; CME, $0.948 \pm 0.022$; CHF, $1.852 \pm 0.035$; EAF, $0.862 \pm 0.018$; AQF, $0.253 \pm 0.016$; PEF, 0.473 \pm 0.016 . (e) Lipid peroxidation inhibition. $\mathrm{IC}_{50}(\mu \mathrm{g} / \mathrm{mL})$ : CAT, $18.23 \pm 0.54$; CME, $92.91 \pm 2.35$; CHF, $33.42 \pm 0.45$; EAF, 137.70 \pm 1.31 ; AQF, 157.63 \pm 3.15 ; $\mathrm{PEF}, 248.20 \pm 2.50$. Catechin (CAT) was used as a reference standard. Results are expressed as mean $\pm \mathrm{SD}(n=3)$. Means with different letters $(a-f)$ differ significantly $(P<0.05)$. CAT, catechin; CME, crude methanolic extract; CHF, chloroform fraction; EAF, ethylacetate fraction; $\mathrm{AQF}$, aqueous fraction; $\mathrm{PEF}$, petroleum ether fraction.

TABle 2: Pearson correlation coefficients of total phenolic, flavonoid, and alkaloid contents with cholinesterase inhibitory and antioxidant activities.

\begin{tabular}{lccr}
\hline & TPC & TFC & TAC \\
\hline AChEI & 0.919 & 0.778 & 0.877 \\
BuChEI & 0.713 & 0.780 & 0.961 \\
DRS & 0.943 & 0.929 & 0.863 \\
HRS & 0.765 & 0.888 & 0.979 \\
LPI & 0.927 & 0.762 & 0.939 \\
FRP & 0.970 & 0.931 & 0.859 \\
TACA & 0.963 & 0.885 & 0.786 \\
\hline
\end{tabular}

AChEI, acetylcholinesterase inhibition; BuChEI, butyrylcholinesterase inhibition; DRS, DPPH radical scavenging; HRS, hydroxyl radical scavenging; LPI, lipid peroxidation inhibition; FRP, ferric reducing power, TACA, total antioxidant capacity.

3.5. Effect of CHF on Spatial Memory and Learning in the Morris Water Maze Task. The time taken by mice of different groups to find the platform (escape latency) in the Morris water maze (MWM) task is shown in Figure 5(a). In the MWM test, the mean latency time (MLT \pm SD) of the normal vehicle group (NVG) to the platform was $33.2 \pm 3.59 \mathrm{sec}$ on the 12th day, abated rapidly during the learning period of the next 3 days, and became $16.6 \pm 4.32 \mathrm{sec}$ on the 15th day. On the other hand, the MLT of the scopolamine (SCO) group decreased slightly with $47.6 \pm 1.24 \mathrm{sec}$ on the 12 th day and $39.6 \pm 2.33 \mathrm{sec}$ on the 15 th day, indicating the marked impairment of memory. In comparison, test groups induced with 100,50 , and $25 \mathrm{mg} / \mathrm{kg}$ of CHF and standard donepezil
(DON) showed MLT of $26.2 \pm 3.36,28.3 \pm 3.59,36.4 \pm 3.12$, and $30.3 \pm 3.03 \mathrm{sec}$, respectively, on the 12 th day and $10.1 \pm 4.21,13.8 \pm 4.32,22.1 \pm 1.88$, and $12.6 \pm 3.87 \mathrm{sec}$, respectively, on the 15th day of the treatment, suggesting the reversal of memory impairment induced by scopolamine $(P<0.05)$.

The times (mean $\pm \mathrm{SD}$ ) spent within the desired quadrant of the NVG, SCO, 100, 50, and $25 \mathrm{mg} / \mathrm{kg}$ of CHF, and DON groups during the probe trial are shown in Figure 5(b). The results showed that NVG, 100, 50, and $25 \mathrm{mg} / \mathrm{kg}$ of CHF, and DON groups spent more time in the desired quadrant in comparison to the SCO, indicating improvement of spatial memory by $\mathrm{CHF}$ in mice $(P<0.05)$. 


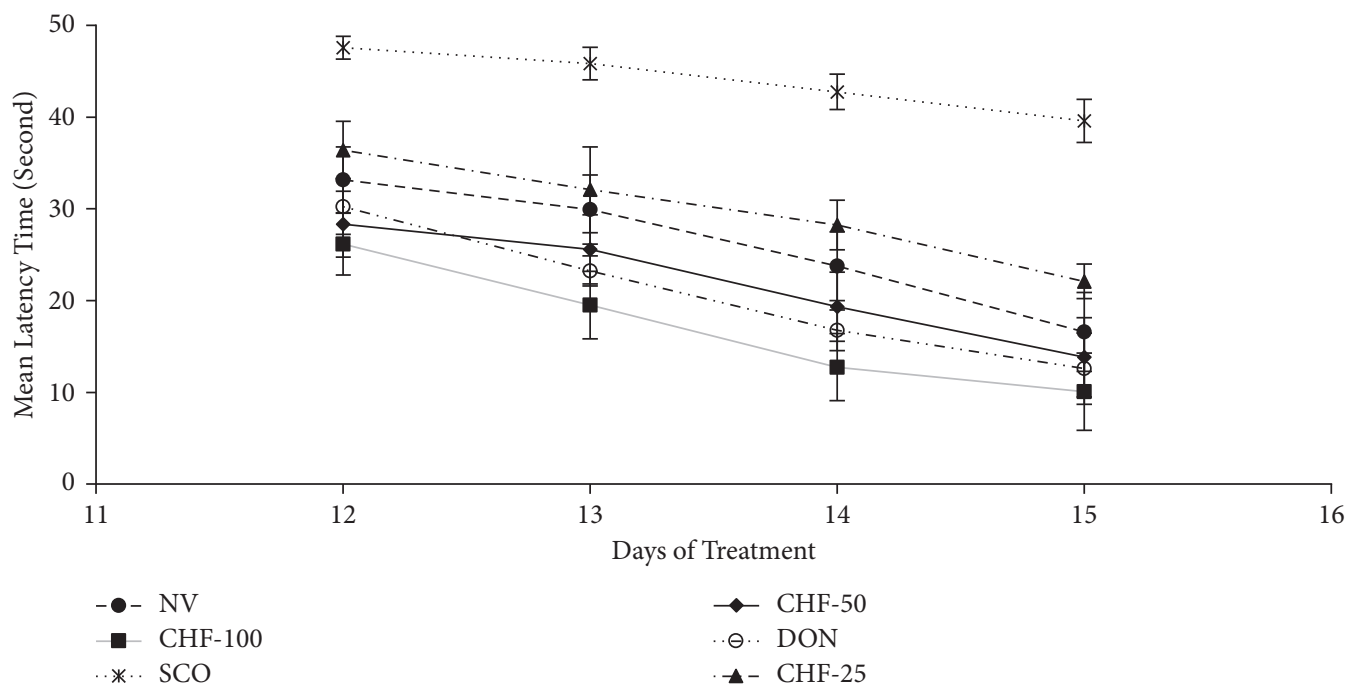

(a)

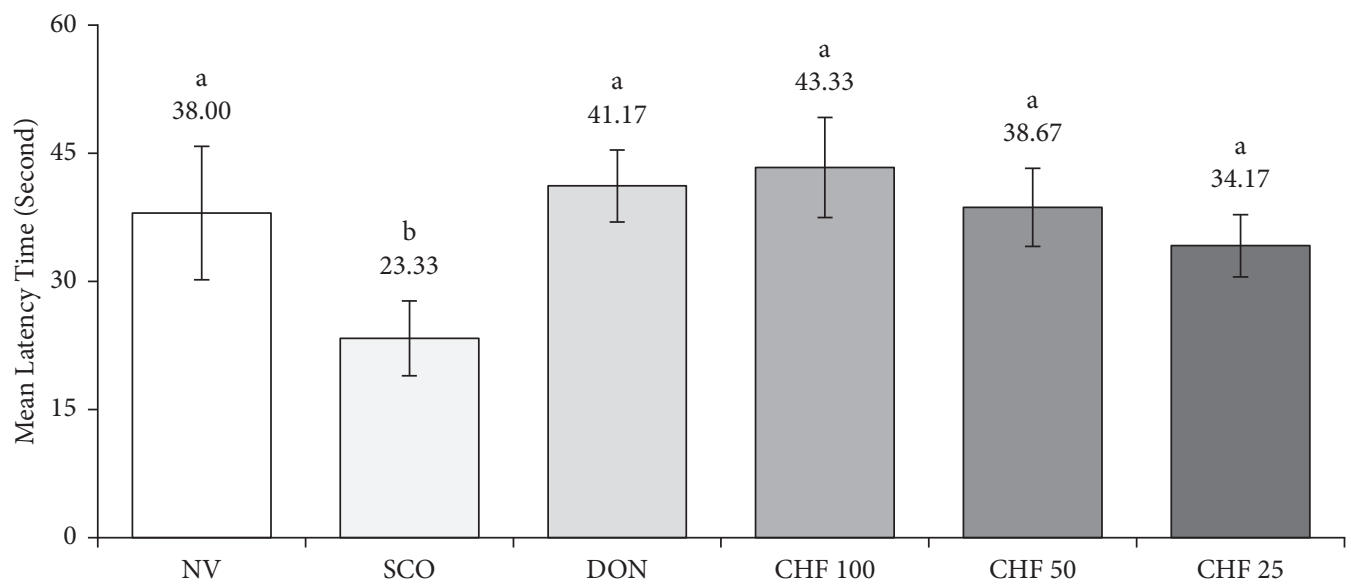

(b)

FIGURE 5: Effect of CHF on scopolamine-induced learning and memory impairments in mice by Morris water maze (MWM) task. (a) Changes in the mean latency time during 4 consecutive days of training for mice of different groups in the MWM task. (b) Average time spent in the platform quadrant by mice of different groups in the MWM probe trial. Each group was significantly different $(P<0.05)$ from the disease control group (scopolamine-treated group). Values were expressed as MLT \pm STD, $n=6$ mice for each group.

\subsection{Effect of CHF on Biochemical Parameters}

3.6.1. AChE Activity in Mouse Brain. AChE activity in mice of the SCO group was increased by 2.13 -fold in comparison to NVG. In contrast, administration of 100,50 , and $25 \mathrm{mg} /$ $\mathrm{kg}$ of $\mathrm{CHF}$ inhibited the AChE activity significantly $(P<0.05)$ in scopolamine-induced mice in a dose-dependent manner, which was similar to that of DON (Figure 6(a)).

3.6.2. $r G S H$ and MDA Level in Mouse Brain. The level of rGSH was decreased significantly $(P<0.05)$ in the brain of SCO group mice compared to NVG. CHF of 100, 50, and $25 \mathrm{mg} / \mathrm{kg}$ increased significantly $(P<0.05)$ the level of $\mathrm{rGSH}$ in scopolamine-induced mice. On the other hand, the level of MDA was increased significantly $(P<0.05)$ as compared to NVG and CHF of 100,50 , and $25 \mathrm{mg} / \mathrm{kg}$ decreased significantly $(P<0.05)$ the level of MDA in scopolamine- induced mice The rGSH and MDA levels were reversed to almost normal by both CHF of $100 \mathrm{mg} / \mathrm{kg}$ and DON treatment (Figures 6(b) and 6(c)).

3.6.3. SOD and CAT Activity in Mouse Brain. The activity of SOD and CAT was reduced significantly $(P<0.05)$ in the brain of the SCO group as compared to NVG. CHF of 100, $50,25 \mathrm{mg} / \mathrm{kg}$ and DON increased $(P<0.05)$ significantly the SOD and CAT activity in scopolamine-induced mice (Figures 6(d) and 6(e)).

3.7. Characterization of CHF by TLC, UV, and IR Spectroscopy. Since CHF showed a potential neuroprotective effect in mice, we used thin layer chromatography (TLC) and a combination of UV and IR spectroscopy to analyze the compounds in the fraction. TLC analysis showed five major compounds (C1 to C5) with $R_{f}$ values of 0.581 , 


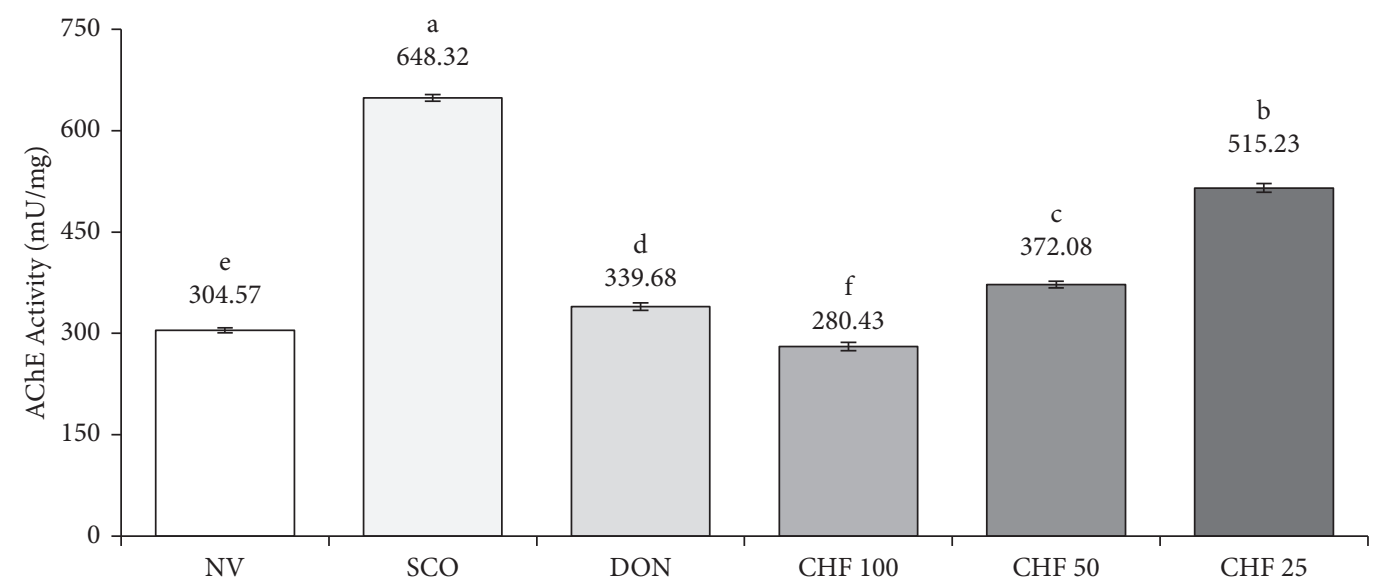

(a)

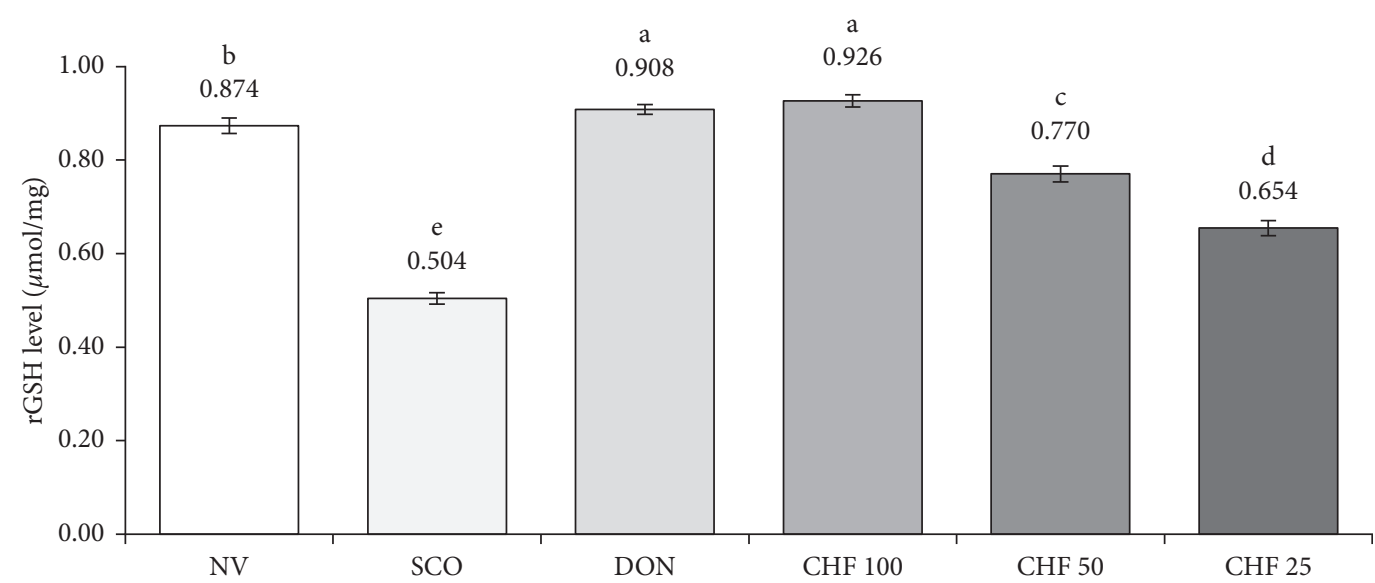

(b)

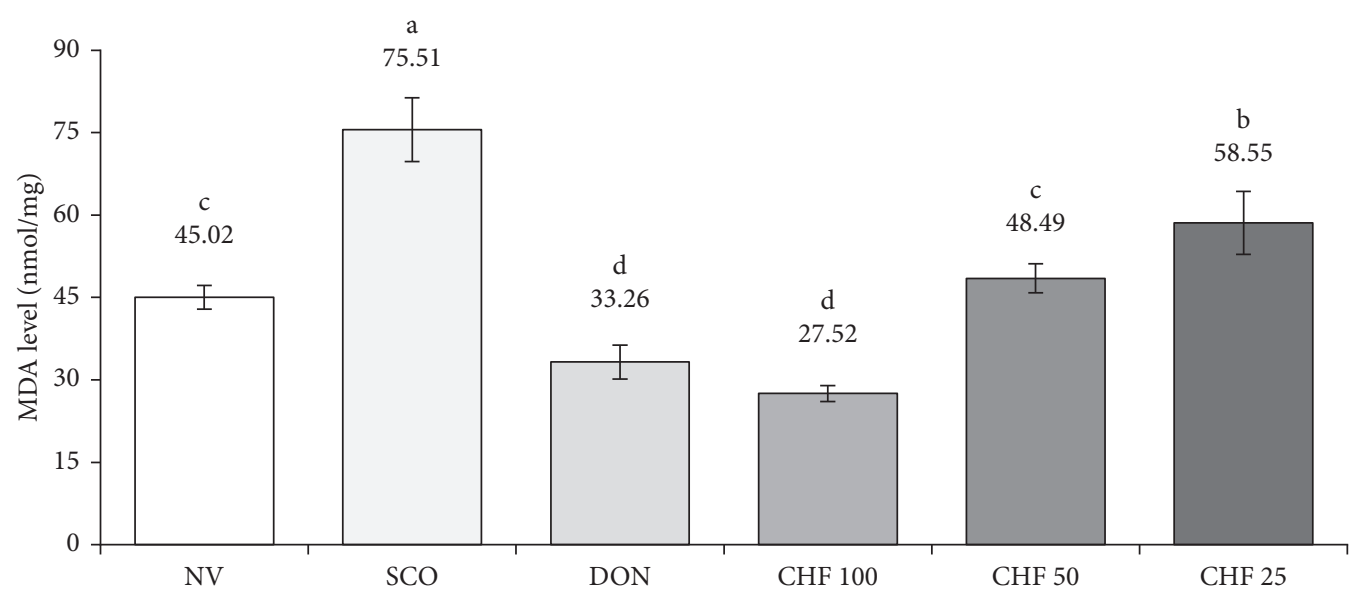

(c)

FIgURE 6: Continued. 


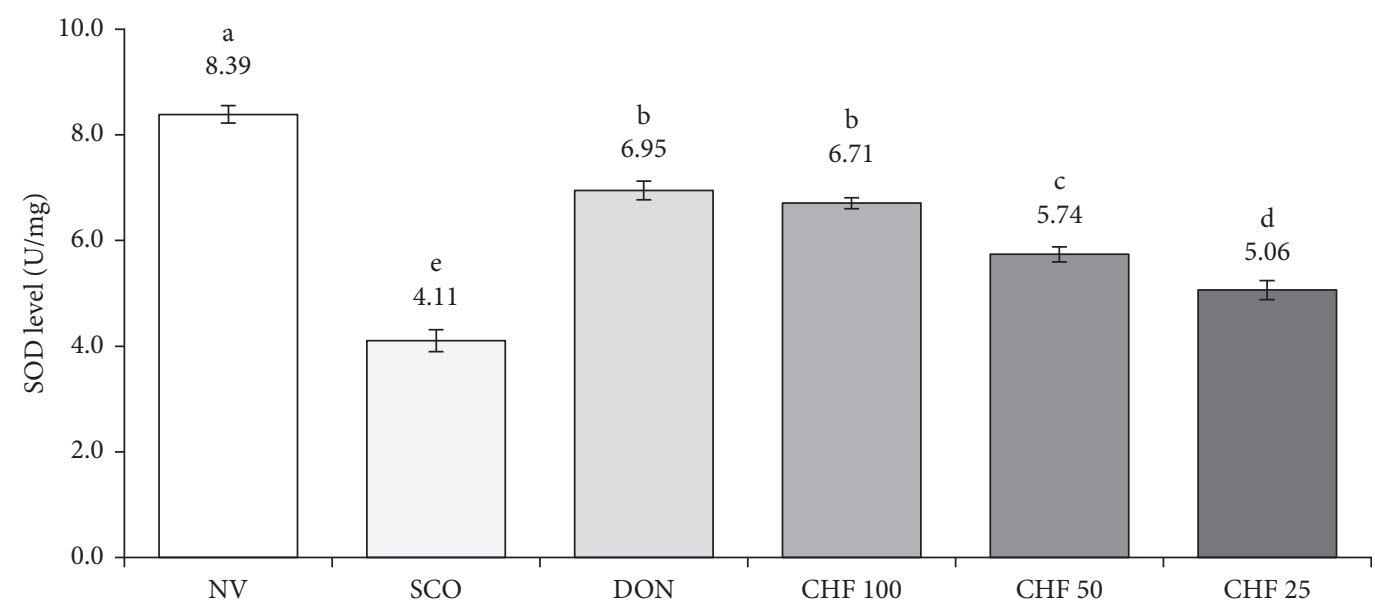

(d)

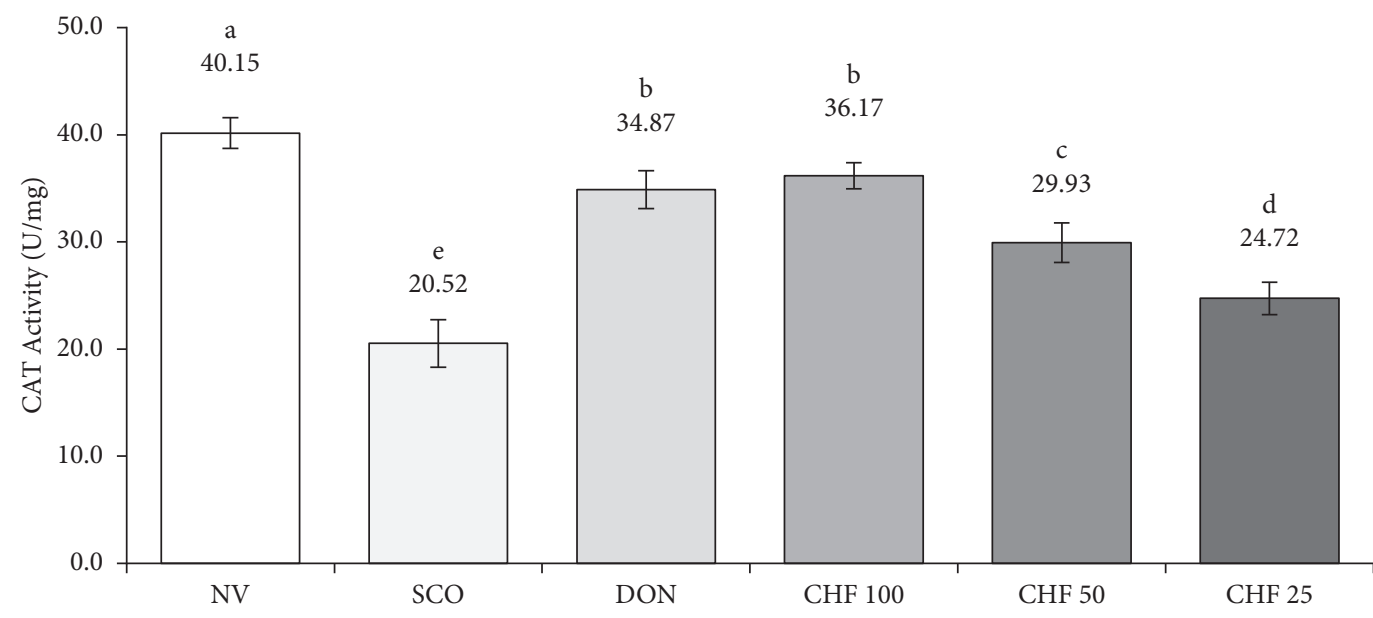

(e)

FIgURE 6: Effect of CHF on brain AChE activity and oxidative stress biomarkers in the scopolamine-induced mouse model. (a) AChE activity, (b) rGSH level, (c) MDA level, (d) SOD activity, and (e) CAT activity in the brain of different groups of mice. Means with different letters (a-f) differ significantly $(P<0.05)$, where all the drug-treated groups were significantly different $(P<0.05)$ from the disease control group (scopolamine-treated group). Values were expressed as mean \pm STD, $n=6$ mice for each group. AChE, acetylcholinesterase; NV, normal vehicle group; SCO, scopolamine; DON, donepezil; CHF, chloroform fraction; rGSH, reduced glutathione; MDA, malondialdehyde; CAT, catalase.

$0.372,0.302,0.244$, and 0.186 (Figure $7(\mathrm{a})$ ). All the compounds were stained as positive in Dragendorff's reagent, indicating that they were alkaloid in nature. The UV spectrum (Figure $7(\mathrm{~b})$ ) of the fraction showed absorption maxima at $270 \mathrm{~nm}$, indicating the presence of alpha, betaunsaturated carbonyl functionalities. IR spectrum (Figure 7(c)) displayed characteristic absorption bands at $3420,1634,1419,1280$, and $1096 \mathrm{~cm}^{-1}$ attributable to hydroxyl and carbonyl groups as well as aromatic functionalities.

\section{Discussion}

$\mathrm{AD}$ is a neurological disorder of aged people clinically characterized by gradual loss of memory and cognition. Numerous etiologic factors have been recognized in $\mathrm{AD}$, among which acetylcholine, A-beta, and tau proteins play crucial roles in the pathogenesis [1]. According to cholinergic hypothesis, the progressive decline of acetylcholine in $\mathrm{AD}$ is closely related to the loss of memory and cognition $[4,5]$. This hypothesis has formed the basis for developing the current $\mathrm{AD}$ drugs. A-beta protein is thought to be central in the pathogenesis of $\mathrm{AD}$ as it is excessively generated in $\mathrm{AD}$, undergoes aggregation, and results in neurotoxicity and neuronal damage. One of the neurotoxic pathways of A-beta is the generation of free radicals that damage all the biomolecules and produce oxidative stress $[7,8]$. Oxidative stress has also been found to be associated with the loss of memory and cognition. Due to the multifactorial nature of $\mathrm{AD}$, a multitargeted drug rather than a single targeted drug has now been suggested and explored as the therapeutics for $\mathrm{AD}$ [37]. In recent years, many efforts have focused on medicinal herbs, which are employed in traditional medicine to treat $\mathrm{AD}$ or related disorders. Stephania japonica is a perennial twining shrub used as the traditional medicine in the treatment of headache, vertigo, 


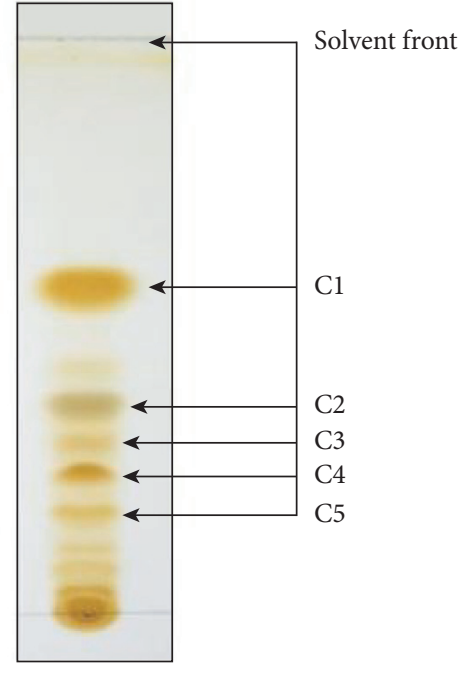

(a)

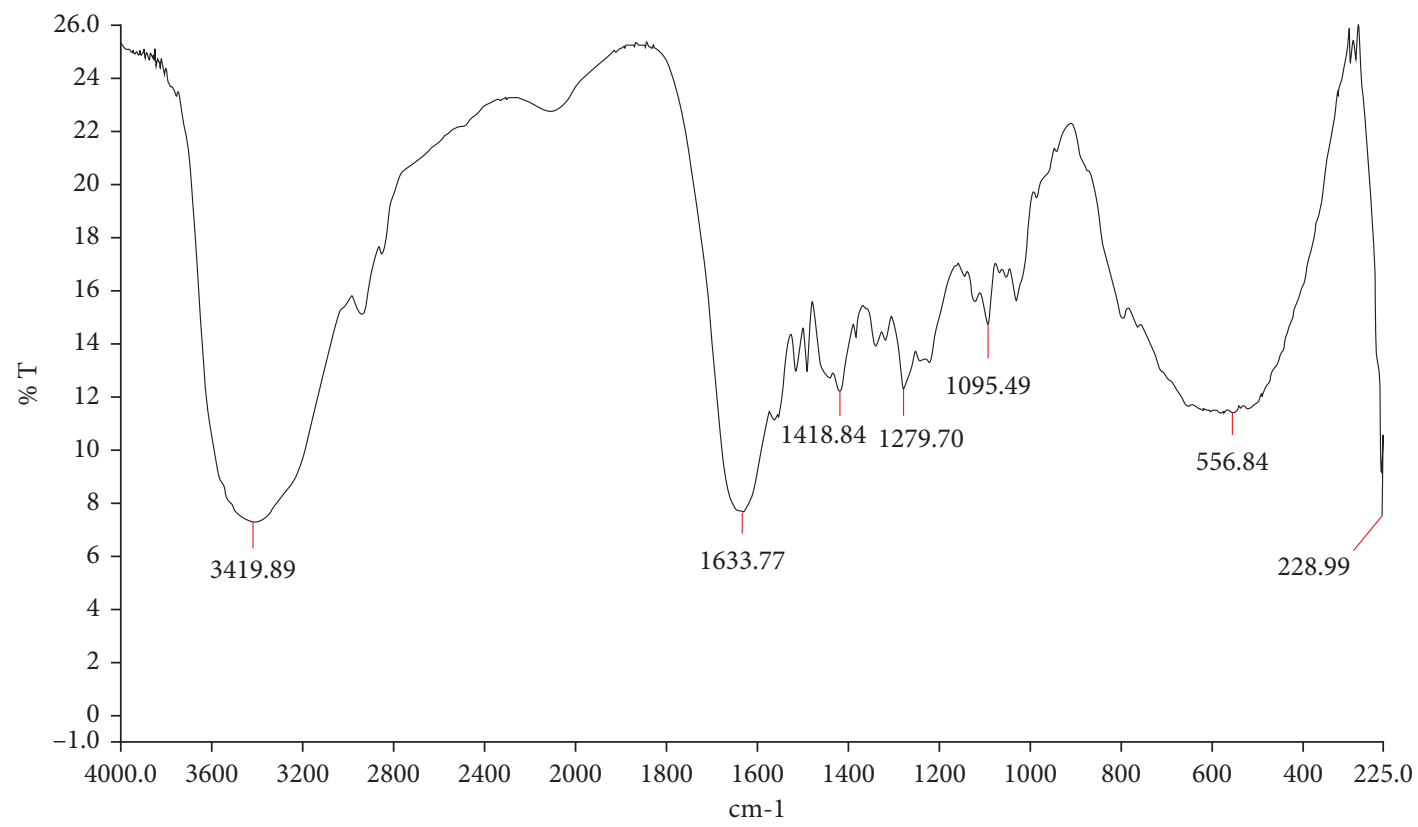

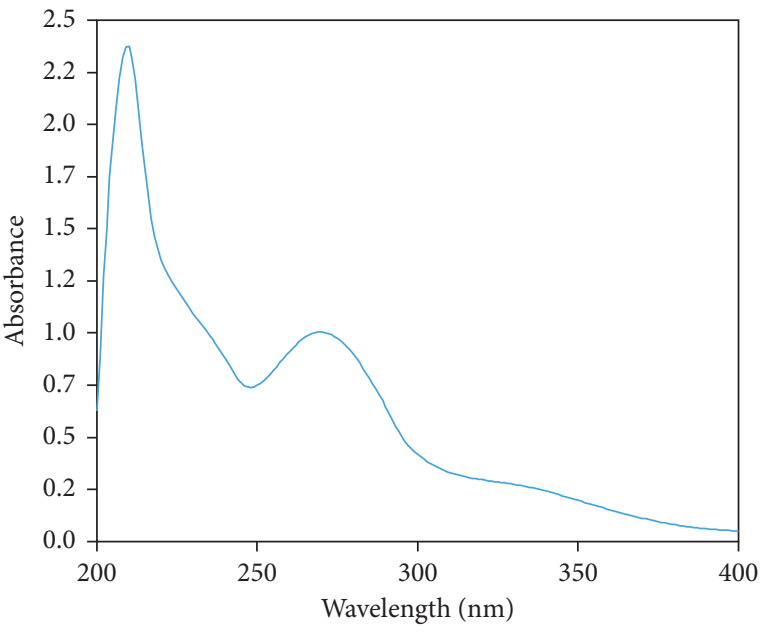

(b)

(c)

FIGURE 7: Chromatographic and spectroscopic characterization of the CHF. (a) Thin layer chromatography (TLC) profile, (b) UV spectrum, and (c) IR spectrum of CHF.

and sleep disturbances and as a tonic in Bangladesh $[9,10]$. Herein, we report for the first time that Stephania japonica has potential anticholinesterase and antioxidant activities in vitro and in vivo and is able to ameliorate the scopolamineinduced deficits in learning and memory.

The crude methanol extract of S. japonica was fractionated into four different fractions such as PEF, CHF, EAF, and $\mathrm{AQF}$ for phytochemical and biological investigation. Preliminary analysis of phytochemicals revealed that the plant is rich in alkaloids and polyphenolics (phenolics and flavonoids), which were mostly found in the CHF (Supplementary Table S-1). Polyphenolics and alkaloids are common secondary metabolites of plants that display important biological activities. Polyphenolics are considered natural antioxidants due to the presence of hydroxyl group and have the ability to scavenge free radicals by donating electron or hydrogen. Alkaloids have been reported to exert multiple biological activities, including antioxidant and acetylcholinesterase inhibitory activity [37]. Quantitative analysis of polyphenolics and alkaloid content revealed that the CHF contained the highest content of phenolics (313.06 mg GAE/g dried extract), flavonoids (167.25 mg CE/ g dried extract), and alkaloids (216.97 mg AE/g dried extract), followed by EAF, AQF, and PEF (Table 1). These results were in good agreement with the previous reports that showed the occurrence of phenolic hasubanan alkaloids as the major compounds in the CHF $[13,14]$. The presence of a large amount of polyphenolics and alkaloids in the CHF 
and its high antioxidant and cholinesterase inhibitory properties suggest that they might be attributable to the bioactivity of the extracts.

$\mathrm{AChE}$ is a key component of the central cholinergic system and a primary enzyme involved in the hydrolysis of ACh into acetic acid and choline. Like AChE, BuChE also hydrolyzes acetylcholine, but to a lesser extent. Inhibition of $\mathrm{AChE}$ and BuChE has been found to increase the endogenous level of ACh neurotransmitter, elevate the cholinergic neurotransmission in the brain, and result in improvement of learning and memory $[17,38]$. In this investigation, we found that all the tested extracts and fractions exhibited a dose-dependent inhibition of AChE and BuChE enzymes (Figure 2). Among them, CHF showed the highest activity with $\mathrm{IC}_{50}$ of 40.06 and $18.78 \mu \mathrm{g} / \mathrm{mL}$ for $\mathrm{AChE}$ and BuChE, respectively. The lower $\mathrm{IC}_{50}$ value of the fraction against the $\mathrm{BuChE}$ than that against $\mathrm{AChE}$ suggests that the fraction has a higher specificity for BuChE than that of AChE. The TPC, TFC, and TAA contents were high in the CHF. Pearson correlation showed a significant association between TAC and BuChE inhibition and between TPC and AChE inhibition (Table 2). We also investigated the inhibition kinetics of the chloroform fraction against both $\mathrm{AChE}$ and BuChE by using a Lineweaver-Burk plot. The Lineweaver-Burk plot (Figure 3) showed that all the data lines intersect at a point on $X$-axis, indicating the noncompetitive inhibition of both AChE and BuChE.

Oxidative stress has recently been recognized as a common pathway of neurotoxicity in many neurodegenerative diseases, including $\mathrm{AD}$. It is extensive in $\mathrm{AD}$ and play roles in the progression and development of AD. Antioxidants have been shown to prevent oxidative stress-induced damage and improve memory in the animal models of $\mathrm{AD}$ $[37,39]$. In this study, we have assessed the antioxidant activity of CME and its fractions using several antioxidant assays such as DPPH and hydroxyl radical scavenging, reducing power, and total antioxidant activity. In all assays, $\mathrm{CHF}$ showed the highest activity compared to the other extract/fractions (Figure 4). The antioxidant activity of the $\mathrm{CHF}$ appeared to be strong when compared to the reference standard catechin. The $\mathrm{IC}_{50}$ of the $\mathrm{CHF}$ for $\mathrm{DPPH}$ and hydroxyl radical scavenging was 5.01 and $17.12 \mu \mathrm{g} / \mathrm{mL}$, while it was 3.03 and $9.00 \mu \mathrm{g} / \mathrm{mL}$ for catechin. Similarly, the reducing activity and total antioxidant activity of the $\mathrm{CHF}$ were 2.49 and 1.85 at $100 \mu \mathrm{g} / \mathrm{mL}$, while they were 2.54 and 2.15 for catechin. The antioxidant activity was also reflected in lipid peroxidation inhibition. CHF effectively inhibited the lipid peroxidation with an $\mathrm{IC}_{50}$ value of $33.42 \mu \mathrm{g} / \mathrm{mL}$. In many plants, the antioxidant activity has been found to be correlated with the phenolics and flavonoids content [39]. We also found a strong correlation between TPC and DRS, LPI, FRP, and TAC and between TAC and HRS and LPI (Table 2). The cholinesterase inhibitory and antioxidant activities of the CHF suggest that it might be effective in preventing or reducing the impairment of memory caused by cholinergic deficit and oxidative stress in $\mathrm{AD}$.

The protective effect of the most potent $\mathrm{CHF}$ on impairment of learning and memory was evaluated in the scopolamine-induced mouse model of memory impairment.
We chose this model as it recapitulates the important features of $\mathrm{AD}$, like oxidative stress, cholinergic deficit, and toxicity $[30,40]$. Scopolamine affects the cholinergic function by inhibiting muscarinic receptor and impairs memory and function. The improvement of learning and memory was measured by the Morris water maze task. In our study, we found a significant increase of the mean latency time in the 4-day treatment with scopolamine compared with the control, indicating that cognitive impairment was induced by scopolamine (Figure 5(a)). Scopolamine also reduced the latency time spent in the probe (target quadrant) as compared with the control group (Figure 5(b)). These results were in accordance with that of the previous works [38]. The mean latency and time spent in the probe were reversed to normal by the CHF and the reference compound donepezil. Our results demonstrated the therapeutic effect of CHF in the improvement of learning and memory.

The mechanisms by which the CHF ameliorated the impairment of memory and cognition in scopolamine-induced mice were explored. It has been reported that the impairment of memory in the scopolamine-induced animal model is associated with cholinergic dysfunction and oxidative stress [40]. Scopolamine has been found to induce an increased level of AChE and oxidized molecules such as MDA and rGSH and reduction of antioxidative enzymes such as SOD and CAT in the brain of model mice, which are considered as oxidative stress biomarkers. In this study, we have measured the level of $\mathrm{AChE}$ and oxidative stress markers in the brain of scopolamine-treated mice. There was a significant increase in AChE activity in mice treated with scopolamine compared with normal mice (Figure 6(a)). These results were consistent with the results reported earlier [38]. The increase of AChE was reversed to a normal level by treatment of CHF and donepezil. Similar to AChE, there was a significant increase of rGSH and MDA levels (Figures 6(b) and $6(\mathrm{c})$ ) and reduction of SOD and CAT levels when compared with the control group (Figures 6(d) and 6(e)). These effects were reversed by treatment with the $\mathrm{CHF}$ and donepezil, suggesting that the CHF is capable of reducing the oxidative stress in scopolamine-treated mice. Taken together, our results indicate that the CHF contributes to improving the ability of learning and memory through inhibition of AChE and oxidative stress.

To gain insights into the compounds responsible for the activity, we investigated further the $\mathrm{CHF}$ by thin layer chromatography (TLC) and a combination of UV and IR spectroscopy. TLC profile of the CHF showed five distinct compounds (Figure 7(a)) and they were positive in Dragendorff's reagent, suggesting that the compounds were alkaloid in nature. UV and IR spectrum of the fraction showed the presence of hydroxyl and alpha, beta-unsaturated carbonyl groups and aromatic functionalities (Figures 7(b) and 7(c)). Importantly, the UV and IR spectrum of the chloroform fraction appears very similar to that of hasubanan alkaloids, as reported earlier [41]. A literature review has shown hasubanan alkaloids as the major compounds isolated from this plant and nearly 50 alkaloids of this class have been reported from different plants of the genus $[13,14]$. Based on the TLC profile, UV and IR 
spectrum of the CHF and a comparison with the previously isolated compounds from this plant suggest that the hasubanan alkaloids are possibly the major compounds of the $\mathrm{CHF}$, which might be involved in the cholinesterase inhibition and antioxidant activity. Further works on isolation and characterization of the active compounds in the chloroform fraction are underway.

\section{Conclusion}

In summary, the results of this study clearly demonstrate that the chloroform fraction of Stephania japonica possesses potential anticholinesterase and antioxidant activities in vitro and in vivo and is able to ameliorate the scopolamineinduced deficits in learning and memory. Our data suggest that the chloroform fraction may represent a promising candidate for treating Alzheimer's disease. To the best of our knowledge, this is the first report of antioxidant, anticholinesterase, and memory-enhancing potentials of S. japonica. With further validation, the chloroform fraction of S. japonica holds a great optimism to be useful in both the prevention and treatment of Alzheimer's disease.

\section{Data Availability}

The data used to support the findings of this study are available from the corresponding author upon request.

\section{Conflicts of Interest}

The authors declare that they have no known conflicts of interest.

\section{Acknowledgments}

The authors gratefully acknowledge the University Grants Commission of Bangladesh for providing financial support (37-01-0000-073-04-012/2019) for this project.

\section{Supplementary Materials}

Table S1: qualitative phytochemical screening of different extracts from S. japonica. . (Supplementary Materials)

\section{References}

[1] T. Guo, D. Zhang, Y. Zeng, T. Y. Huang, H. Xu, and Y. Zhao, "Molecular and cellular mechanisms underlying the pathogenesis of Alzheimer's disease," Molecular Neurodegeneration, vol. 15, no. 1, p. 40, 2020.

[2] P. Davies and A. J. Maloney, "Selective loss of central cholinergic neurons in Alzheimer's disease," Lancet, vol. 2, no. 8000 , p. $1403,1976$.

[3] F. Collin, C. Cheignon, and C. Hureau, "Oxidative stress as a biomarker for Alzheimer's disease," Biomarkers in Medicine, vol. 12, no. 3, pp. 201-203, 2018.

[4] A. V. Terry Jr. and J. J. Buccafusco, "The cholinergic hypothesis of age and Alzheimer's disease-related cognitive deficits: recent challenges and their implications for novel drug development," Journal of Pharmacology and Experimental Therapeutics, vol. 306, no. 3, pp. 821-827, 2003.
[5] L. M. Bierer, V. Haroutunian, S. Gabriel et al., "Neurochemical correlates of dementia severity in Alzheimer's disease: relative importance of the cholinergic deficits," Journal of Neurochemistry, vol. 64, no. 2, pp. 749-760, 1995.

[6] A. Atri, "Current and future treatments in alzheimer's disease," Seminars in Neurology, vol. 39, no. 2, pp. 227-240, 2019.

[7] L. Lyras, N. J. Cairns, A. Jenner, P. Jenner, and B. Halliwell, "An assessment of oxidative damage to proteins, lipids, and DNA in brain from patients with Alzheimer's disease," Journal of Neurochemistry, vol. 68, no. 5, pp. 2061-2069, 1997.

[8] D. A. Butterfield and D. Boyd-Kimball, " $\beta$ Oxidative stress, amyloid- $\beta$ peptide, and altered key molecular pathways in the pathogenesis and progression of alzheimer's disease," Journal of Alzheimer's Disease, vol. 62, no. 3, pp. 1345-1367, 2018.

[9] A. Ghani, Medicinal Plants of Bangladesh, The Asiatic Society of Bangladesh, Dhaka, Bangladesh, 2nd edition, 2003.

[10] S. Rudra, K. N. Islam, M. M. Rahman, and S. B. Uddin, "Medicinal plant diversity and their therapeutic uses in selected village common forests in chittagong hill tracts, Bangladesh," Journal of Herbs, Spices, \& Medicinal Plants, vol. 27, no. 1, pp. 83-107, 2021.

[11] M. Moniruzzaman, M. S. Hossain, and P. S. Bhattacharjee, "Evaluation of antinociceptive activity of methanolic extract of leaves of Stephania japonica Linn," Journal of Ethnopharmacology, vol. 186, pp. 205-208, 2016.

[12] M. Hossain, M. A. K. Azad, S. M. Tareq, and M. T. Islam, "Botanical and phyto-pharmacological reports on Stephania japonica," International Journal of Applied Pharmaceutical Sciences and Research, vol. 2, no. 1, pp. 154-160, 2017.

[13] D. K. Semwal, R. Badoni, R. Semwal, S. K. Kothiyal, G. J. P. Singh, and U. Rawat, "The genus Stephania (Menispermaceae): chemical and pharmacological perspectives," Journal of Ethnopharmacology, vol. 132, no. 2, pp. 369-383, 2010.

[14] A. R. Carroll, T. Arumugan, J. Redburn et al., "Hasubanan alkaloids with $\delta$-opioid binding affinity from the aerial parts of Stephania japonica," Journal of Natural Products, vol. 73, no. 5, pp. 988-991, 2010.

[15] M. N. Uddin, N. U. Ahmed, M. A. Rahman, R. Akter, and R. Akter, "Antioxidative potential of the polyphenolics ofStephania japonicavar. Discolor (blume) forman: a chromatographic (high-performance liquid chromatography) and spectrophotometric measure," International Journal of Food Properties, vol. 19, no. 4, pp. 911-928, 2016.

[16] S. Morris Kupchan, "Recent advances in the chemistry of terpenoid tumor inhibitors," Pure and Applied Chemistry, vol. 21, no. 2, pp. 227-246, 1970.

[17] M. N. Uddin, R. Afrin, M. J. Uddin et al., "Vanda roxburghii chloroform extract as a potential source of polyphenols with antioxidant and cholinesterase inhibitory activities: identification of a strong phenolic antioxidant," BMC Complementary and Alternative Medicine, vol. 15, no. 1, p. 195, 2015.

[18] V. L. Singleton, R. Orthofer, and R. M. Lamuela-Raventós, "Analysis of total phenols and other oxidation substrates and antioxidants by means of folin-ciocalteu reagent," Oxidants and Antioxidants Part A, vol. 299, pp. 152-178, 1999.

[19] V. Dewanto, X. Wu, K. K. Adom, and R. H. Liu, “Thermal processing enhances the nutritional value of tomatoes by increasing total antioxidant activity," Journal of Agricultural and Food Chemistry, vol. 50, no. 10, pp. 3010-3014, 2002.

[20] M. Ajanal, M. Gundkalle, and S. Nayak, "Estimation of total alkaloid in Chitrakadivati by UV-Spectrophotometer," $A n$ cient Science of Life, vol. 31, no. 4, pp. 198-201, 2012. 
[21] G. L. Ellman, K. D. Courtney, V. Andres Jr., and R. M. Featherstone, "A new and rapid colorimetric determination of acetylcholinesterase activity," Biochemical Pharmacology, vol. 7, no. 2, pp. 88-95, 1961.

[22] T. Palmer, Understanding Enzymes, Prentice Hall/Ellis Horwood, London, UK, 4th edition, 1995.

[23] A. Braca, N. De Tommasi, L. Di Bari, C. Pizza, M. Politi, and I. Morelli, "Antioxidant principles from Bauhinia tarapotensis," Journal of Natural Products, vol. 64, no. 7, pp. 892-895, 2001.

[24] B. Halliwell, J. M. C. Gutteridge, and O. I. Aruoma, "The deoxyribose method: a simple "test-tube" assay for determination of rate constants for reactions of hydroxyl radicals," Analytical Biochemistry, vol. 165, no. 1, pp. 215-219, 1987.

[25] M. Oyaizu, "Studies on products of browning reaction. Antioxidative activities of products of browning reaction prepared from glucosamine," The Japanese Journal of $\mathrm{Nu}$ trition and Dietetics, vol. 44, no. 6, pp. 307-315, 1986.

[26] F. Liu and T. B. Ng, "Antioxidative and free radical scavenging activities of selected medicinal herbs," Life Sciences, vol. 66, no. 8, pp. 725-735, 2000.

[27] P. Prieto, M. Pineda, and M. Aguilar, "Spectrophotometric quantitation of antioxidant capacity through the formation of a phosphomolybdenum complex: specific application to the determination of vitamin E," Analytical Biochemistry, vol. 269, no. 2, pp. 337-341, 1999.

[28] J. Kim, Y. H. Seo, J. Kim et al., "Casticin ameliorates scopolamine-induced cognitive dysfunction in mice," Journal of Ethnopharmacology, vol. 259, p. 112843, 2020.

[29] R. Morris, "Developments of a water-maze procedure for studying spatial learning in the rat," Journal of Neuroscience Methods, vol. 11, no. 1, pp. 47-60, 1984.

[30] I. Klinkenberg and A. Blokland, "The validity of scopolamine as a pharmacological model for cognitive impairment: a review of animal behavioral studies," Neuroscience \& Biobehavioral Reviews, vol. 34, no. 8, pp. 1307-1350, 2010.

[31] O. Lowry, N. Rosebrough, A. L. Farr, and R. Randall, "Protein measurement with the Folin phenol reagent," Journal of Biological Chemistry, vol. 193, no. 1, pp. 265-275, 1951.

[32] G. L. Ellman, "Tissue sulfhydryl groups," Archives of Biochemistry and Biophysics, vol. 82, no. 1, pp. 70-77, 1959.

[33] H. Esterbauer and K. H. Cheeseman, "Determination of aldehydic lipid peroxidation products: malonaldehyde and 4hydroxynonenal," Oxygen Radicals in Biological Systems Part B: Oxygen Radicals and Antioxidants, vol. 186, pp. 407-421, 1990.

[34] L. Magnani, E. M. Gaydou, and J. C. Hubaud, "Spectrophotometric measurement of antioxidant properties of flavones and flavonols against superoxide anion," Analytica Chimica Acta, vol. 411, no. 1-2, pp. 209-216, 2000.

[35] S. Marklund and G. Marklund, "Involvement of the superoxide anion radical in the autoxidation of pyrogallol and a convenient assay for superoxide dismutase," European Journal of Biochemistry, vol. 47, no. 3, pp. 469-474, 1974.

[36] H. Aebi, "Catalase," Methods of enzymatic analysis, vol. 2, pp. 673-684, 1974.

[37] J. Kim, H. J. Lee, and K. W. Lee, "Naturally occurring phytochemicals for the prevention of Alzheimer's disease," Journal of Neurochemistry, vol. 112, no. 6, pp. 1415-1430, 2010.

[38] B. Wang, Y. Zhong, C. Gao, and J. Li, "Myricetin ameliorates scopolamine-induced memory impairment in mice via inhibiting acetylcholinesterase and down-regulating brain iron," Biochemical and Biophysical Research Communications, vol. 490, no. 2, pp. 336-342, 2017.

[39] N. Karim, H. Khan, I. Khan et al., "An increasing role of polyphenols as novel therapeutics for alzheimer's: a review," Medicinal Chemistry, vol. 16, no. 8, pp. 1007-1021, 2020.

[40] S. Haider, S. Tabassum, and T. Perveen, "Scopolamine-induced greater alterations in neurochemical profile and increased oxidative stress demonstrated a better model of dementia: a comparative study," Brain Research Bulletin, vol. 127, pp. 234-247, 2016.

[41] M. Tomita, T. Ibuka, Y. Inubushil, Y. Watanabe, and M. Matsui, "Studies on the alkaloids of menispermaceuos plants. CCX. Alkaloids of Stephania japonica MIERS. (Suppl. 9). Structure of hasubanonine and homostephanoline). Chemical and pharmaceutical bulletin," Chemical \& Pharmaceutical Bulletin, vol. 13, no. 5, pp. 538-545, 1965. 